\title{
AeroValve Experimental Test Data Final Report
}

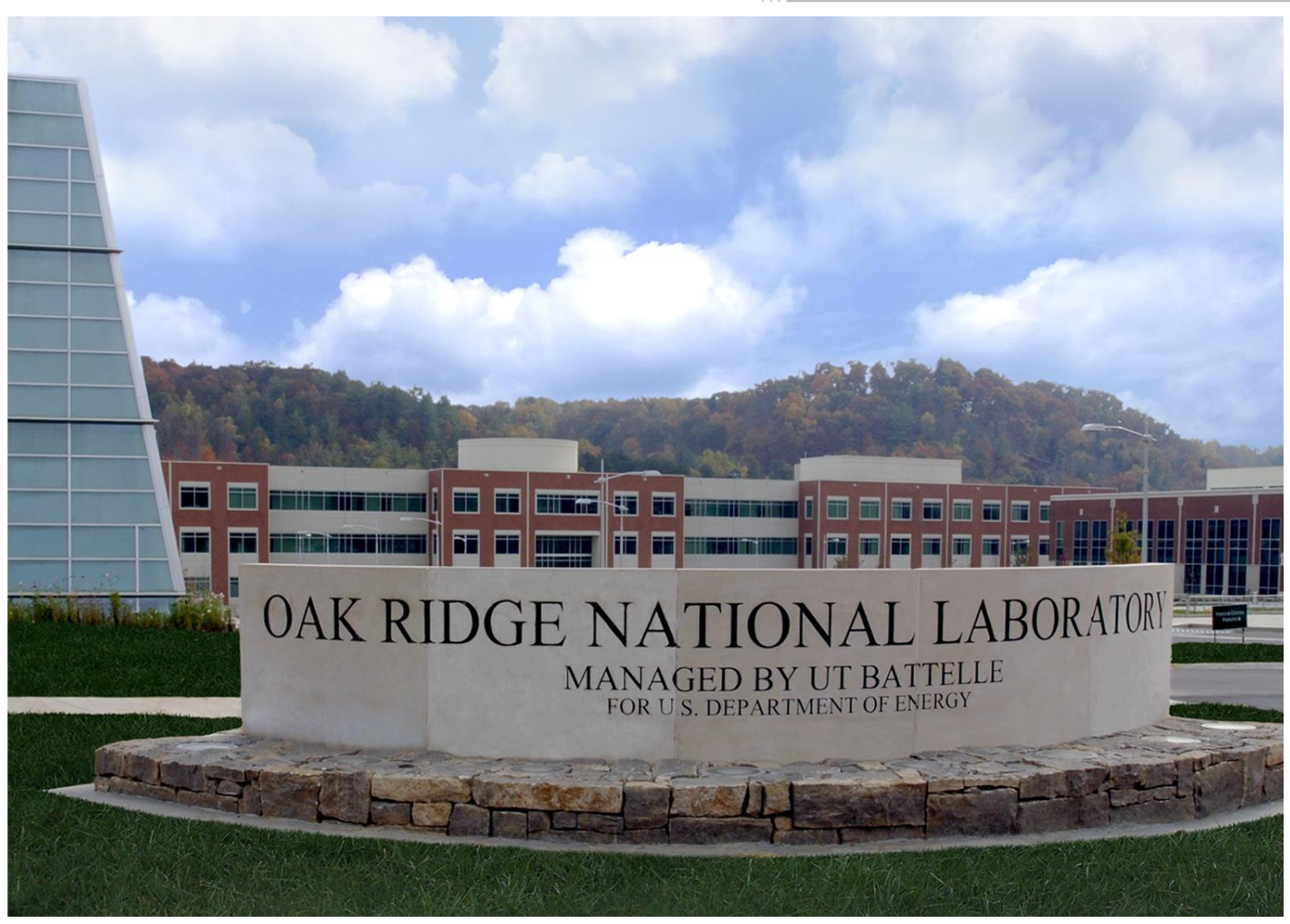

Approved for public release; distribution is unlimited.

Mark Noakes

September 30, 2014 


\section{DOCUMENT AVAILABILITY}

Reports produced after January 1, 1996, are generally available free via US Department of Energy (DOE) SciTech Connect.

Website http://www.osti.gov/scitech/

Reports produced before January 1, 1996, may be purchased by members of the public from the following source:

National Technical Information Service

5285 Port Royal Road

Springfield, VA 22161

Telephone 703-605-6000 (1-800-553-6847)

TDD 703-487-4639

Fax 703-605-6900

E-mail info@ntis.gov

Website http://www.ntis.gov/help/ordermethods.aspx

Reports are available to DOE employees, DOE contractors, Energy Technology Data Exchange representatives, and International Nuclear Information System representatives from the following source:

Office of Scientific and Technical Information

PO Box 62

Oak Ridge, TN 37831

Telephone 865-576-8401

Fax 865-576-5728

E-mail reports@osti.gov

Website http://www.osti.gov/contact.html

This report was prepared as an account of work sponsored by an agency of the United States Government. Neither the United States Government nor any agency thereof, nor any of their employees, makes any warranty, express or implied, or assumes any legal liability or responsibility for the accuracy, completeness, or usefulness of any information, apparatus, product, or process disclosed, or represents that its use would not infringe privately owned rights. Reference herein to any specific commercial product, process, or service by trade name, trademark, manufacturer, or otherwise, does not necessarily constitute or imply its endorsement, recommendation, or favoring by the United States Government or any agency thereof. The views and opinions of authors expressed herein do not necessarily state or reflect those of the United States Government or any agency thereof. 
Manufacturing Demonstration Facility

\title{
AEROVALVE EXPERIMENTAL TEST DATA FINAL REPORT
}

\author{
Mark Noakes
}

Date Published:

September 30, 2014

Prepared by OAK RIDGE NATIONAL LABORATORY

Oak Ridge, Tennessee 37831-6283

managed by

UT-BATTELLE, LLC

for the

US DEPARTMENT OF ENERGY

under contract DE-AC05-00OR22725 



\section{CONTENTS}

\section{Page}

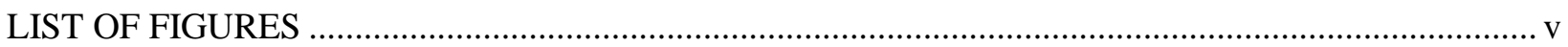

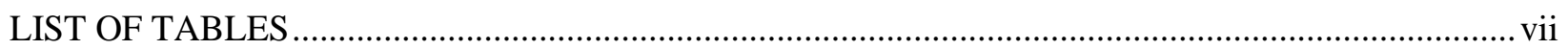

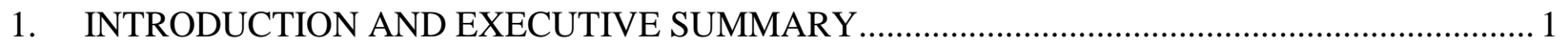

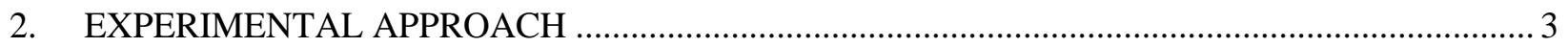

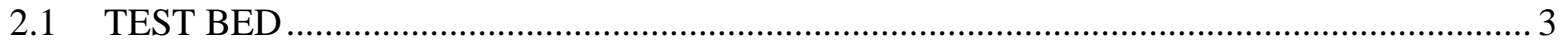

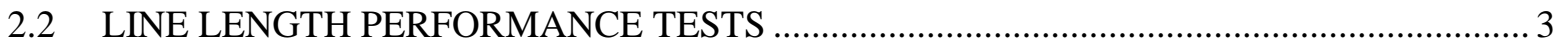

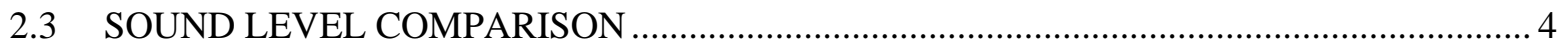

2.4 LOAD TEST COMPARISON

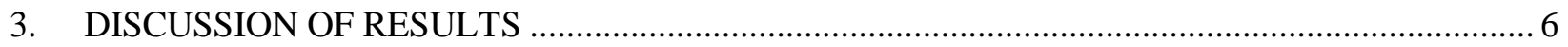

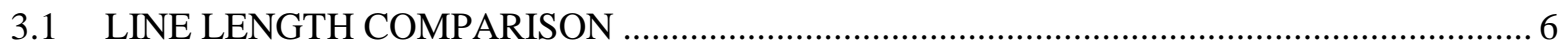

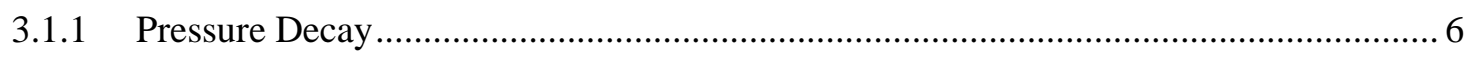

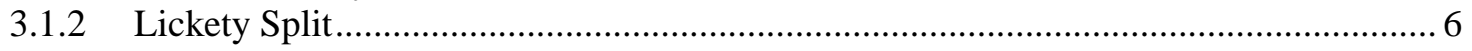

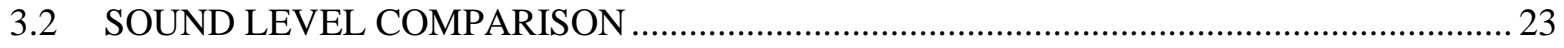

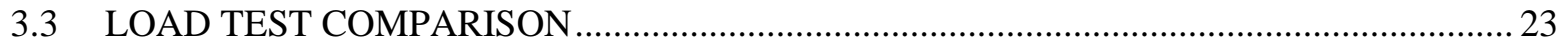

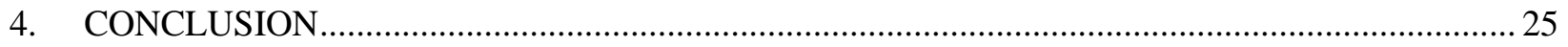

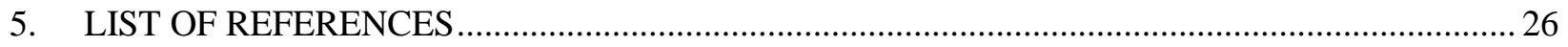





\section{LIST OF FIGURES}

Figure $\quad$ Page

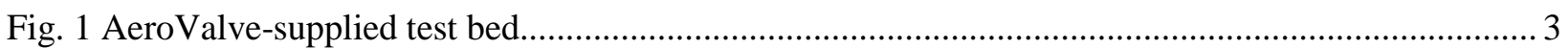

Fig. 2. Load Testing with Constant Force Springs................................................................................ 5

Fig. 3. Pressure Decay with .75s \& 90/80 psi vs. Tubing Length........................................................ 7

Fig. 4. Pressure Decay with 1.0s \& 90/80 psi vs. Tubing Length........................................................ 8

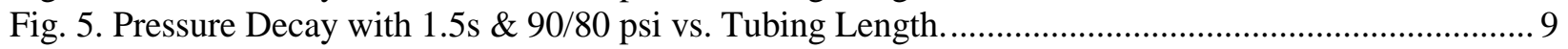

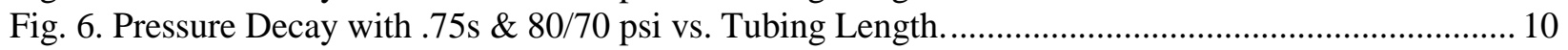

Fig. 7. Pressure Decay with 1.0s \& 80/70 psi vs. Tubing Length....................................................... 11

Fig. 8. Pressure Decay with $1.5 \mathrm{~s} \&$ 80/70 psi vs. Tubing Length........................................................ 12

Fig. 9. Pressure Decay with .75s \& 60/50 psi vs. Tubing Length......................................................... 13

Fig. 10. Pressure Decay with 1.0s \& 60/50 psi vs. Tubing Length....................................................... 14

Fig. 11. Pressure Decay with 1.5s \& 60/50 psi vs. Tubing Length........................................................ 15

Fig. 12. Pressure Decay .75s Mapped Against All Pressures and Line Lengths. ..................................... 16

Fig. 13. Pressure Decay 1.0s Mapped Against All Pressures and Line Lengths. ...................................... 17

Fig. 14. Pressure Decay 1.5s Mapped Against All Pressures and Line Lengths. ..................................... 18

Fig. 15. Pressure Decay with 90/80 psi vs. Time Constants and Line Length......................................... 19

Fig. 16. Pressure Decay with $80 / 70$ psi vs. Time Constants and Line Length....................................... 20

Fig. 17. Pressure Decay with $60 / 50$ psi vs. Time Constants and Line Length........................................... 21

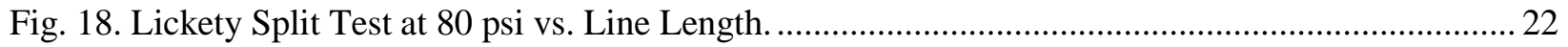

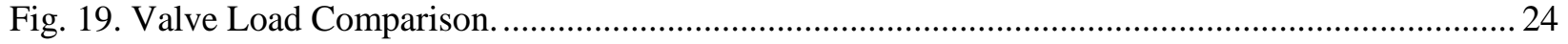





\section{LIST OF TABLES}

Table

Page

Table 1. Pressure Decay with .75s \& 90/80 psi vs. Tubing Length........................................................ 7

Table 2. Pressure Decay with 1.0s \& 90/80 psi vs. Tubing Length........................................................ 8

Table 3. Pressure Decay with 1.5s \& 90/80 psi vs. Tubing Length....................................................... 9

Table 4. Pressure Decay with .75s \& 80/70 psi vs. Tubing Length..................................................... 10

Table 5. Pressure Decay with 1.0s \& 80/70 psi vs. Tubing Length.................................................... 11

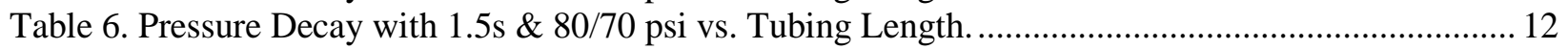

Table 7. Pressure Decay with .75 s \& $60 / 50$ psi vs. Tubing Length...................................................... 13

Table 8. Pressure Decay with 1.0s \& 60/50 psi vs. Tubing Length....................................................... 14

Table 9. Pressure Decay with 1.5s \& 60/50 psi vs. Tubing Length....................................................... 15

Table 10. Pressure Decay with .75s Mapped Against All Pressures and Line Lengths............................ 16

Table 11. Pressure Decay with 1.0s Mapped Against All Pressures and Line Lengths............................. 17

Table 12. Pressure Decay with 1.5s Mapped Against All Pressures and Line Lengths............................. 18

Table 13. Pressure Decay with 90/80 psi vs. Time Constants and Line Length....................................... 19

Table 14. Pressure Decay with 80/70 psi vs. Time Constants and Line Length....................................... 20

Table 15. Pressure Decay with 60/50 psi vs. Time Constants and Line Length..................................... 21

Table 16. Lickety Split Test at 80 psi vs. Line Length......................................................................... 22

Table 17. Sound Level Comparison Between Standard Commercial Valve and AeroValve.................... 23

Table 18. Valve Load Comparison. ................................................................................................... 24 


\section{INTRODUCTION AND EXECUTIVE SUMMARY}

This report documents the collection of experimental test data and presents performance characteristics for the AeroValve brand prototype pneumatic bidirectional solenoid valves tested at the Oak Ridge National Laboratory (ORNL) in July/August 2014 as part of a validation of AeroValve's energy efficiency claims. The test stand and control programs were provided by AeroValve. All raw data and processing are included in the report attachments.

AeroValve's position statement on their valves is best summarized by the following collection of statements from the AeroValve web site:

AeroValve has designed and developed a directional control valve that reduces the amount of compressed air used in pneumatic processes by $20 \%-30 \%$. This novel technology is an elegant solution that recycles a portion of compressed air during a cycle of work. As the valve cycles, the pressurized outbound port connects to the opposing (unpressurized) outlet port, recycling the compressed air from one outbound port to the other. The technology can be applied to approximately $60 \%$ of the existing directional control valves and is designed to be a drop-in, cost competitive replacement in the market. [1].

AeroValve's goal is to improve the efficiency of manufacturing operations that use factory automation based on pneumatic actuation. The AeroValve definition of efficiency is the volume of air consumed per work completed. According to AeroValve's website, manufactures spend between $10 \%$ and up to $30 \%$ of their energy costs to compress air with a total US cost of about $\$ 10$ billion each year [1]. Substantially reducing the volume of air required for pneumatic controls and actuation would reduce the size and cost of plant air generation systems and would reduce utilities operating costs.

This evaluation of the AeroValve valves (AV valves) concludes that the valves performed as well as AeroValve stated, or better, in almost all cases analyzed where air use efficiency is concerned.

Comparisons were made against a standard design commercial valve with the same manifold mounting configuration and intended application range. Measuring air consumption per work completed, the AV valve was as much as $85 \%$ more efficient than the standard valve under some conditions, though absolute performance of both the standard commercial valve and the AV valve varied considerably with the chosen test parameters. However the AV valve was always more efficient than the standard commercial valve for air consumed per work completed for a given set of test conditions. The tests conducted are described in detail in section two of this report.

Besides performance validation, ORNL conducted the first AeroValve tests on the effects of port-A/port$\mathrm{B}$ line length on valve performance. It was thought that long pneumatic lines may store additional energy that could help valve performance. This effect was not seen, possibly due to the restriction posed by the small diameter supply tubing used in these applications. It appears that valve efficiency improves as line length decreases for both the standard commercial valve and the AV valves although the threshold where line length matters was different for each brand of valve. Note that the data presented here includes test data for line lengths from $50 \mathrm{ft}$. down to $1 \mathrm{ft}$. Total loop length are equal to twice the line length.

The AV style valve is slower than a standard commercial valve. Both valves improved (were quicker) as port-A/port-B line length decreased; however the difference between the AV valve and the traditional style commercial valve also widened as tubing line length decreased. For example the difference was only $30 \%$ at $50 \mathrm{ft}$. line length, but it was more than $100 \%$ at extremely short line lengths. Since AeroValve's 
intended target market is for applications where economy of operations is more important than speed of operation, this is not seen as a significant issue.

A limited test using a calibrated sound level meter was completed on sound level produced by the valves during actuation. In the limited test, there was no statistically observable difference in audible sound levels produced by either standard commercial valves or AV valves. A more rigorous test to industry standards may provide more useful information; however subjectively there did not seem to be any difference between the two valves when listening to them during the test. If there is a difference, it is not substantial.

A load test was also conducted using constant force springs of different spring constants. As the load increased, the efficiency of the standard commercial valve was flat, as expected; however the AV valve efficiency increased with load and was substantially more efficient than the standard commercial valve at all loads tested. 


\section{EXPERIMENTAL APPROACH}

\subsection{TEST BED}

AeroValve supplied the test stand, shown in Fig. 1, and two valve test programs installed on a programmable logic controller (PLC). ORNL did not supply any hardware or software for this work other than the tubing for the tubing length tests and the hardware for the load tests. Air was supplied by a .4kW Werther International compressor and stored in a separate five gallon Craftsman air tank. Solenoid valves controlled compressor output and tank output. A pressure sensor was used to regulate the test pressure according to the experimental parameters.

\subsection{LINE LENGTH PERFORMANCE TESTS}

The valves to be tested were mounted in a commercial manifold block fed by $1 / 4$-inch tubing. The length of the two tubing lines between the pneumatic control valve and the actuator (port-A and port-B) was varied as a matched set (length was equal). For each length of tubing, all four valves (one standard commercial valve and three AV valves) were installed in turn on the manifold and tested for both test cases outlined below. The tubing was then cut to length for the next test. Tubing was varied in length in 5 $\mathrm{ft}$. increments from $50 \mathrm{ft}$. down to $10 \mathrm{ft}$. and then in $1 \mathrm{ft}$. increments from $9 \mathrm{ft}$. down to $1 \mathrm{ft}$. Port-A and port-B lines were kept at the same length throughout the process. An indicated length of $10 \mathrm{ft}$. in the data means that each line was $10 \mathrm{ft}$. long for a total loop length of $20 \mathrm{ft}$.

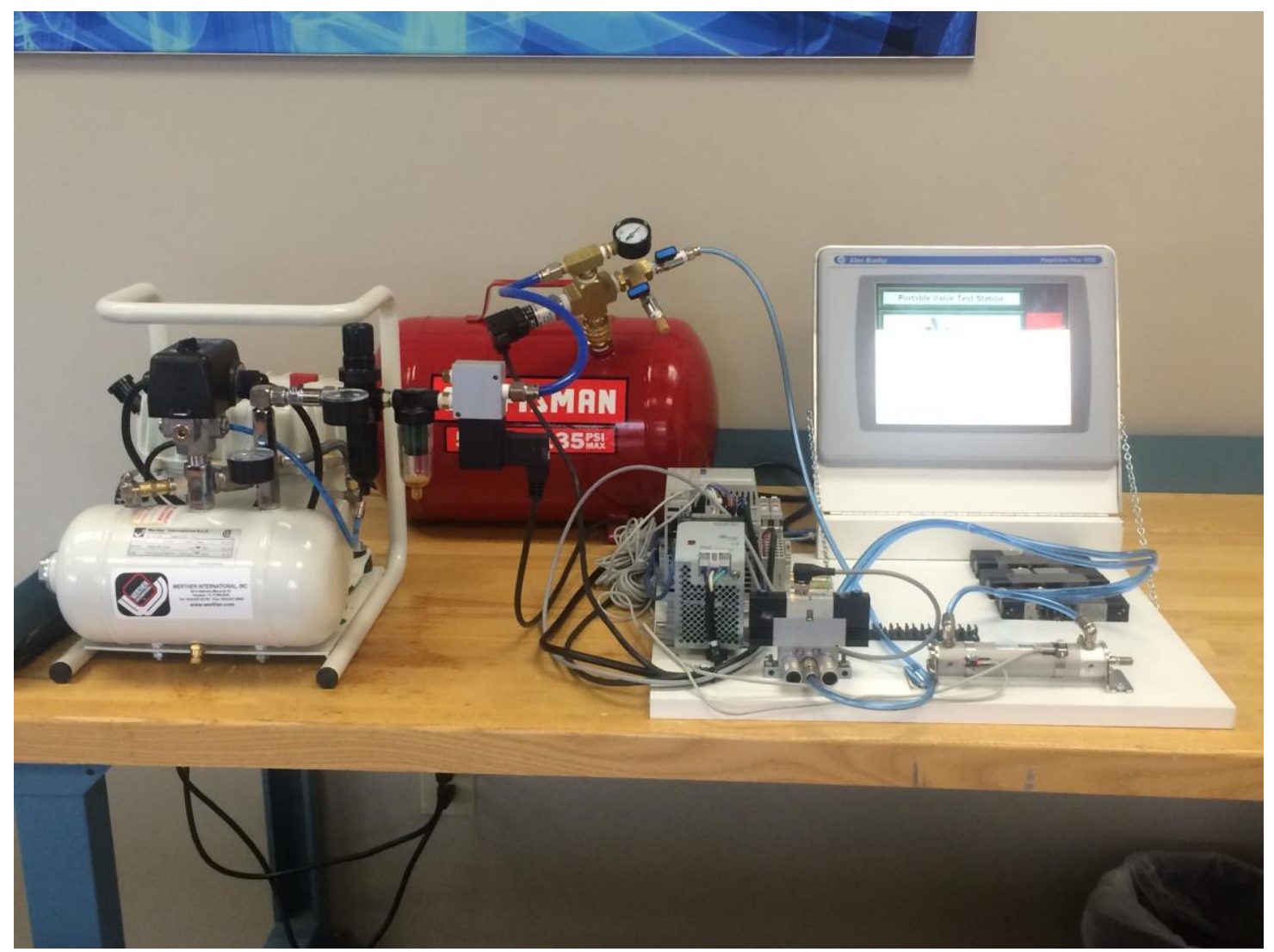

Fig. 1 AeroValve-supplied test bed. 
Interface to the PLC programs was via graphical user interface (GUI). Operator interaction was via touchscreen. Adjustable parameters were set for each block of tests as required.

The first test (Pressure Decay) measured how much work could be completed with each valve by setting a start and stop pressure on the supply air and then cycling the tested valves back and forth until the specified amount of air had been expended as indicated by pressure drop on the feed tank. A cycle is defined as one stroke of the valve in one direction; it does not include the return motion to the starting position. For each test case, pressure and actuation delay times were varied for 90/80psi, 80/70psi, and $60 / 50 \mathrm{psi}$ and $.75 \mathrm{~s}, 1.00 \mathrm{~s}$, and $1.5 \mathrm{~s}$ for a total of nine test cases at each line length. The recorded result was the number of valve cycles achieved over the specified pressure drop at the specified start and stop pressures. To monitor consistency, each specific case was run for five instances for $50 \mathrm{ft}$ down to $9 \mathrm{ft}$; it was determined that the data was highly consistent over sampling so the test instances were dropped to three for the last data sets. Data was recorded into Excel spreadsheets. While final documentation includes all raw test data, the plots in this document were generated by averaging the results of the three AeroValve data sets of five (or three) instances each for a total of 15 samples (or nine for three instances). The standard commercial valve was averaged over five instances. (Each valve was run five times under the same parameters except for the last data sets where three instances were run at the same parameters.) While all data is available in the spreadsheets, $10-\mathrm{ft}, 5-\mathrm{ft}, 3-\mathrm{ft}$, and 1-ft were used in the graphical analysis since it appeared that there was no additional detail provided by the additional resolution at the low end.

The second test (Lickety Split) was designed to measure comparative actuation time of the standard commercial valve and AV valves. While the AeroValve design provides a gain in efficiency, the design also causes slower actuation than the standard commercial valve. This test measured the amount of time that it took the valve-driven actuator to cycle 30 times at a nominal 80 psi tank supply pressure; however it should be noted that the pressure did vary over the test as the compressor could not maintain pressure against the rapid cycling of the actuator. Although the software controlled the switching of the task based on reaching the specified pressure, actual pressures were not recorded by the test software. A sensor was mounted on each end of the actuator motion limit. When the cylinder activated either sensor, the direction was reversed as quickly as possible. Each valve test case was also run five instances (except for the lower range data as described above), and the AV valve cases were averaged to produce one data point for the plots. However each data point is available in the raw data soft copy attached to this report.

All valve tests were completed with the actuator unloaded for the line length tests.

\subsection{SOUND LEVEL COMPARISON}

A sound level test was conducted to determine if there was any difference in the sound generated by the AV valves vs. the standard commercial valve. Typical sound testing according to ISO3744 involves a highly controlled (quiet) special environment with an array of microphones connected to a data acquisition system [2]. Equipment and facilities for ISO3744 testing were not available; however a comparative (relative, not absolute) test was devised using a calibrated industrial hygiene grade $\mathrm{dB}$ meter in the quietest room available during off hours.

The test was completed using the AeroValve test bed. The compressor, valve assembly, and linear actuator are collocated in close proximity to one another, and each is a source of sound. No sound level measurements were taken while the compressor was running. The valves appeared to be the primary noise source over that of the linear actuator (cylinder), and the microphone of the $\mathrm{dB}$ meter was placed two inches from the exhaust ports of the valves during the test. 
The test meter was a Quest Technologies 1100 Precision Sound Level Meter. Settings used included: 30 $100 \mathrm{~dB}$ range, weighting A (industrial frequency range), fast response mode, and maximum value encountered. For each run, the meter readout was reset after the compressor had stopped running and before data collection had begun.

\subsection{LOAD TEST COMPARISON}

A load test of the AV valves was conducted to determine how the unique air saving properties might impact the actuator's load capabilities. A comparative test was devised to measure performance at 0,25 , and $50 \mathrm{lb}$. loads. The chosen load force method used constant force springs as it was felt that this would produce more useful results than weights on a suspended mechanism. However this did limit testing to the use of available products. The springs chosen were $24.8 \mathrm{lbs}$. and $40.9 \mathrm{lbs}$. with a $\pm 10 \%$ possible variation along the useful length of the spring.

The constant force springs were mounted in a spool test fixture clamped to the test table as shown in Fig. 2. The AeroValve test stand was clamped to the table at a sufficient distance that the spring would be operated well within its working range. An adapter was fabricated to mount the end of the constant force spring on the threaded end of the linear actuator (cylinder). There was consideration given to mounting the actuator in both the horizontal and vertical orientations for testing; however use of the constant force spring approach to load should negate any differences due to orientation while guaranteeing that test stand components (primarily the actuator) would not be damaged if some misalignment (creating side loads) were encountered in the test mockup.

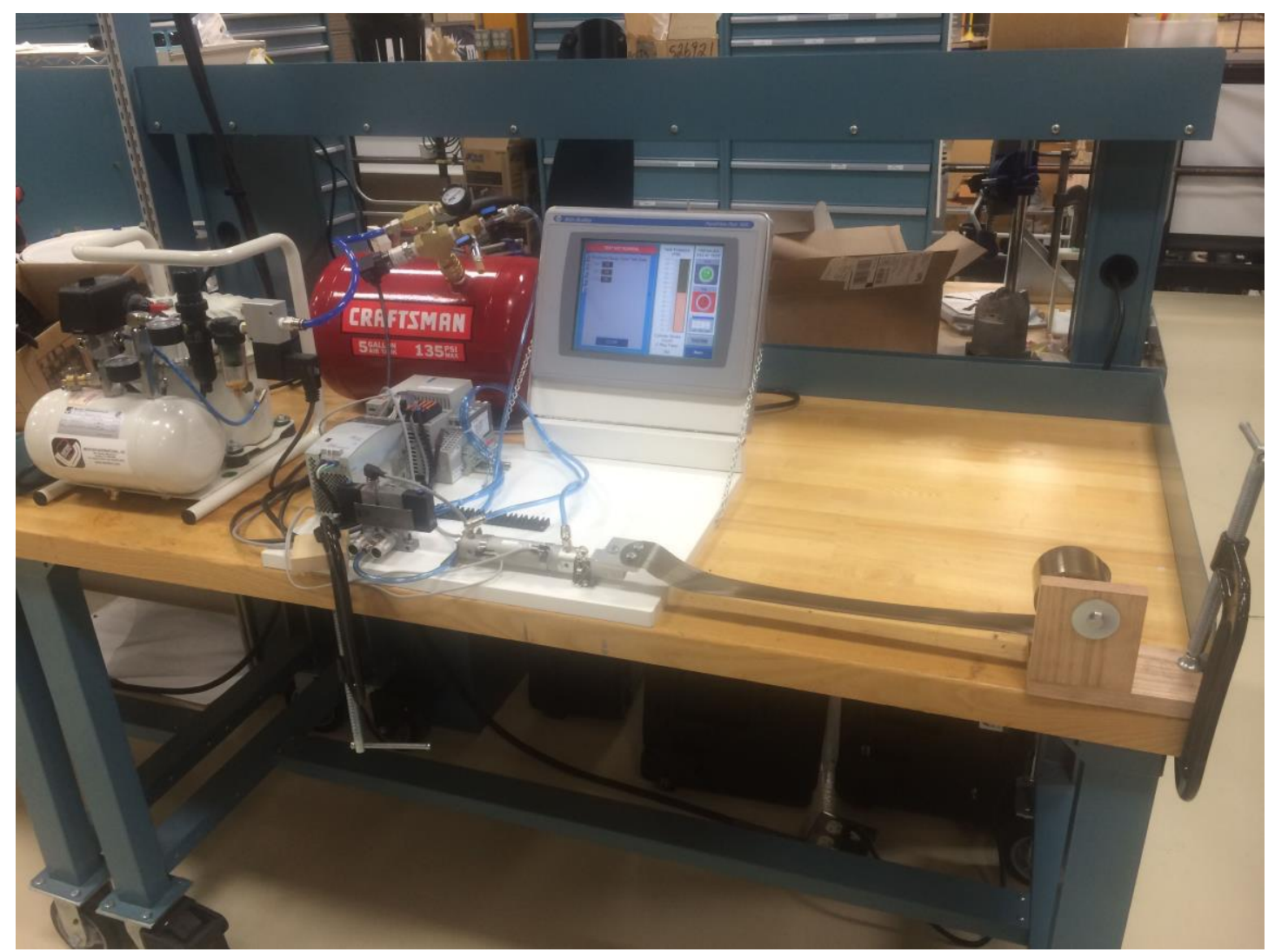

Fig. 2. Load Testing with Constant Force Springs. 


\section{DISCUSSION OF RESULTS}

\subsection{LINE LENGTH COMPARISON}

\subsubsection{Pressure Decay}

AeroValve had previously tested their valves with a line (loop) length of six feet between valve and actuator with a stated efficiency advantage over traditional commercial valves of approximately 20 $30 \%$. It was found that this advantage, though always in the AeroValve favor, varied greatly by valve-toactuator tubing length, supply pressure, and programmed actuation delay time, and the results became more nonlinear as that tubing length became shorter. In some cases this efficiency advantage is more than $80 \%$. In general both the standard commercial valve and AV valves perform better at shorter line lengths. This data is presented in Tables $1-9$ and Figures $3-11$.

It appears that AeroValve efficiency is higher for lower supply pressures when the delay time is short. When the delay time is long, the standard commercial valve and AV valve performance tend to converge as line length gets longer. Tables $10-12$ and Figures $12-14$ show the trends for fixed delay time with varying pressure. Note that there are some delay time instances where the standard commercial valve with short time delay is as efficient as the AV valve with longer time delay. At long supply line lengths and long delay times, the traces overlap to the point that the best standard commercial valve performance is better than the worst AeroValve performance.

An increase in the delay time from $.75 \mathrm{~s}$ to $1.00 \mathrm{~s}$ to $1.5 \mathrm{~s}$ decreased the efficiency of the valves for longer line length. However as line length became shorter, performance converged to approximately the same points for any delay time. Standard commercial valve convergence happened at approximately $25 \mathrm{ft}$. line length; AV valve convergence happened at approximately $10 \mathrm{ft}$. line length. The AV valve is more sensitive to line length and delay time than the standard commercial valve. It was also noticed that shorter delay times caused the performance of the AV valve to be flatter over longer lengths of supply line. This data is shown in Tables $13-15$ and Figures $15-17$.

The AeroValve design appears to be better than the standard commercial valve design in efficiency (work per volume of air) for long line lengths and short delay time. When the line length is long and the delay time is long, the AV valve advantage over the standard commercial valve is at its minimum, but it still exists. Both AV valves and the standard commercial valve perform best at the shortest possible line lengths.

\subsubsection{Lickety Split}

AeroValve had previously conducted this test only at the six-foot line (loop) length. For all line lengths the AeroValve design is slower to actuate than the typical standard commercial design; this value can be over $100 \%$ and tends to increase as the supply line gets shorter. It should also be noted that while decreasing the line length to shorter than five feet, the AV valve did not continue to improve (move more quickly). Data is shown in Table 16 and Fig. 18. 
Table 1. Pressure Decay with $.75 \mathrm{~s} \&$ 90/80 psi vs. Tubing Length.

\begin{tabular}{|c|c|c|}
\hline $\begin{array}{c}\text { Line Length in ft. } \\
\text { Standard Commercial Valve } \\
\text { Averages (cycles) }\end{array}$ & $\begin{array}{c}\text { AV Valve } \\
\text { Averages (cycles) }\end{array}$ \\
\hline 50 & 17 & 30.9 \\
\hline 45 & 17 & 31.6 \\
\hline 40 & 17 & 31.6 \\
\hline 35 & 16.6 & 31.6 \\
\hline 30 & 16.8 & 30.8 \\
\hline 25 & 18 & 31 \\
\hline 20 & 18.2 & 31.1 \\
\hline 15 & 21 & 31.9 \\
\hline 10 & 24.4 & 35.2 \\
\hline 5 & 30 & 41.7 \\
\hline 3 & 32.7 & 45 \\
\hline 1 & 36.7 & 49.1 \\
\hline
\end{tabular}

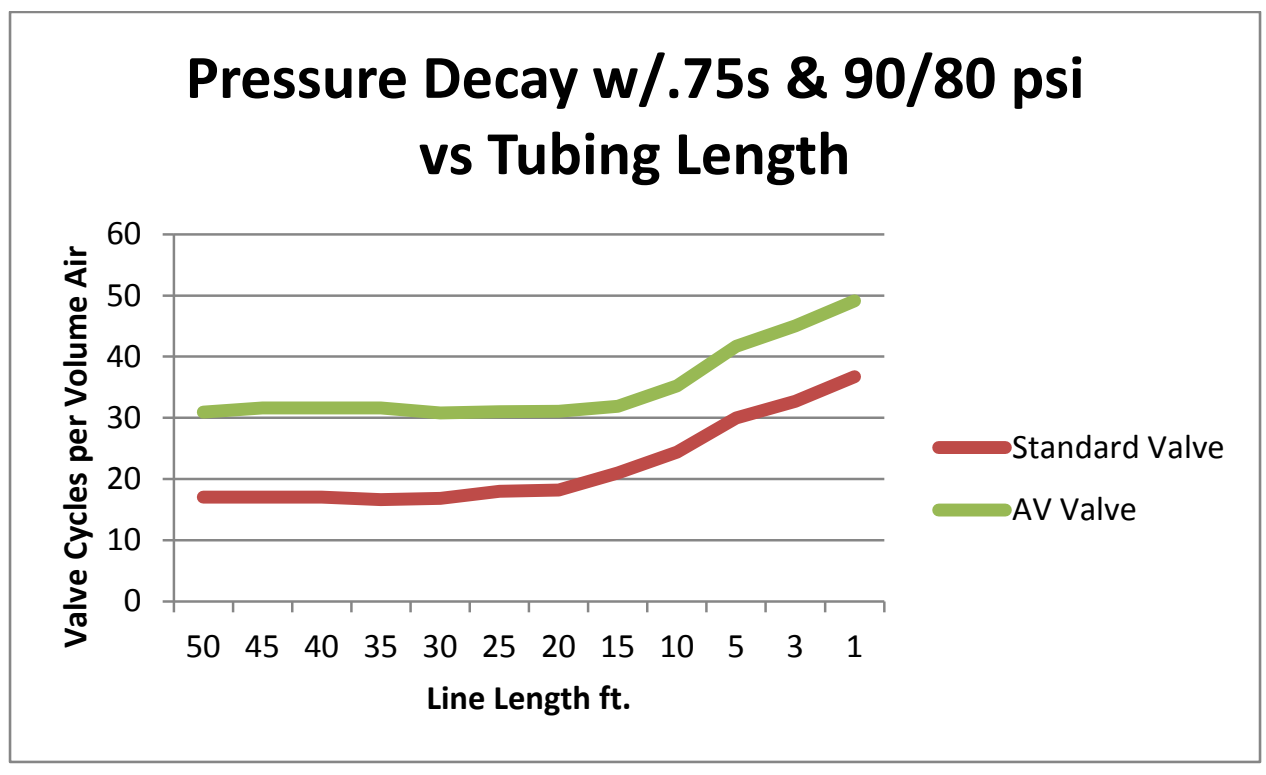

Fig. 3. Pressure Decay with $.75 \mathrm{~s} \& \mathbf{9 0 / 8 0}$ psi vs. Tubing Length. 
Table 2. Pressure Decay with $1.0 s \&$ 90/80 psi vs. Tubing Length.

\begin{tabular}{|c|c|c|}
\hline $\begin{array}{c}\text { Line Length in ft. } \\
\text { Standard Commercial Valve } \\
\text { Averages (cycles) }\end{array}$ & $\begin{array}{c}\text { AV Valve } \\
\text { Averages (cycles) }\end{array}$ \\
\hline 50 & 14 & 22.1 \\
\hline 45 & 13.8 & 22.1 \\
\hline 40 & 13.8 & 21.7 \\
\hline 35 & 14 & 21.6 \\
\hline 30 & 16.8 & 23.5 \\
\hline 25 & 18 & 26.3 \\
\hline 20 & 18.8 & 26.5 \\
\hline 15 & 21 & 30.4 \\
\hline 10 & 24.6 & 35.4 \\
\hline 5 & 30.3 & 42 \\
\hline 3 & 33 & 45.3 \\
\hline 1 & 37 & 49.7 \\
\hline
\end{tabular}

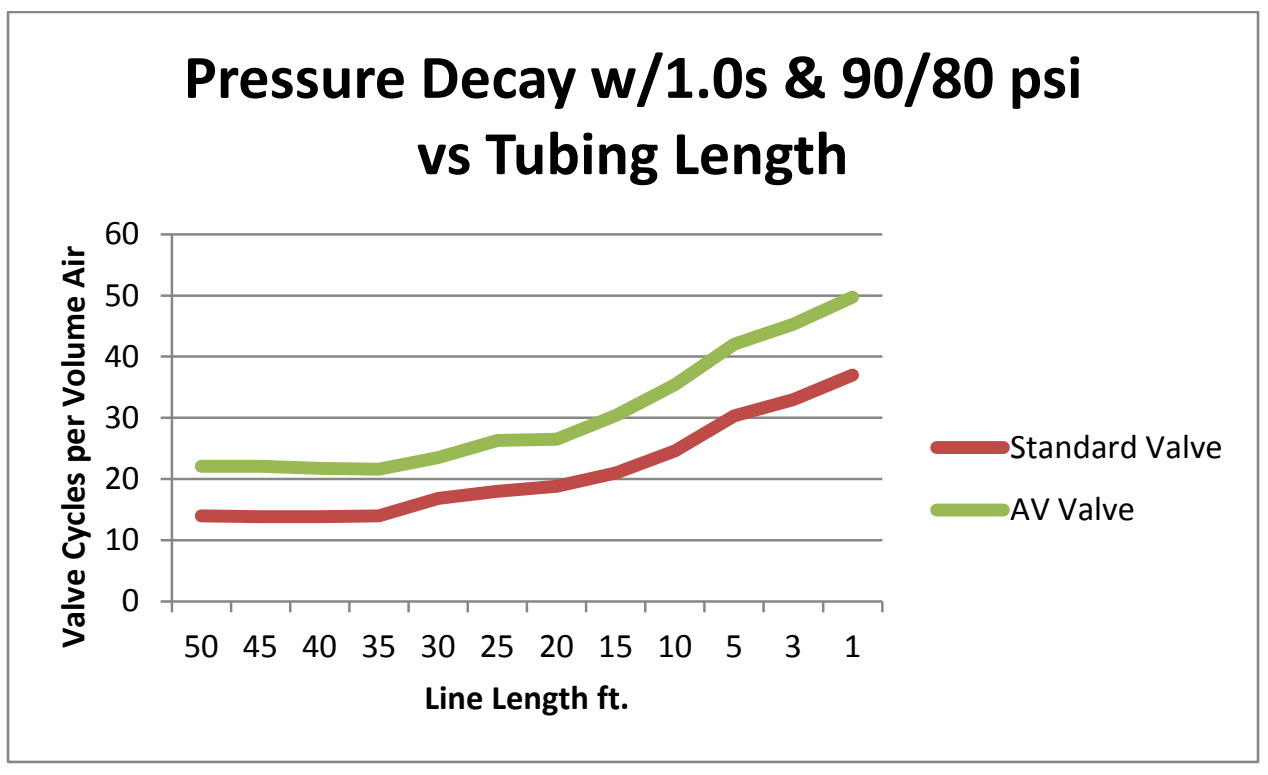

Fig. 4. Pressure Decay with $1.0 s \&$ 90/80 psi vs. Tubing Length. 
Table 3. Pressure Decay with $1.5 s \& 90 / 80$ psi vs. Tubing Length.

\begin{tabular}{|c|c|c|}
\hline $\begin{array}{c}\text { Line Length in ft. } \\
\text { Standard Commercial Valve } \\
\text { Averages (cycles) }\end{array}$ & $\begin{array}{c}\text { AV Valve } \\
\text { Averages (cycles) }\end{array}$ \\
\hline 50 & 10.4 & 14.6 \\
\hline 45 & 11 & 15.3 \\
\hline 40 & 11.8 & 15.9 \\
\hline 35 & 12.8 & 17.3 \\
\hline 30 & 16 & 22.3 \\
\hline 25 & 18.8 & 26.2 \\
\hline 20 & 18.8 & 26.3 \\
\hline 15 & 20.8 & 30.6 \\
\hline 10 & 25 & 35.6 \\
\hline 5 & 31 & 42.1 \\
\hline 3 & 33.7 & 45.4 \\
\hline 1 & 37.7 & 49.8 \\
\hline
\end{tabular}

\section{Pressure Decay w/1.5s and $90 / 80$ psi vs Tubing Length}

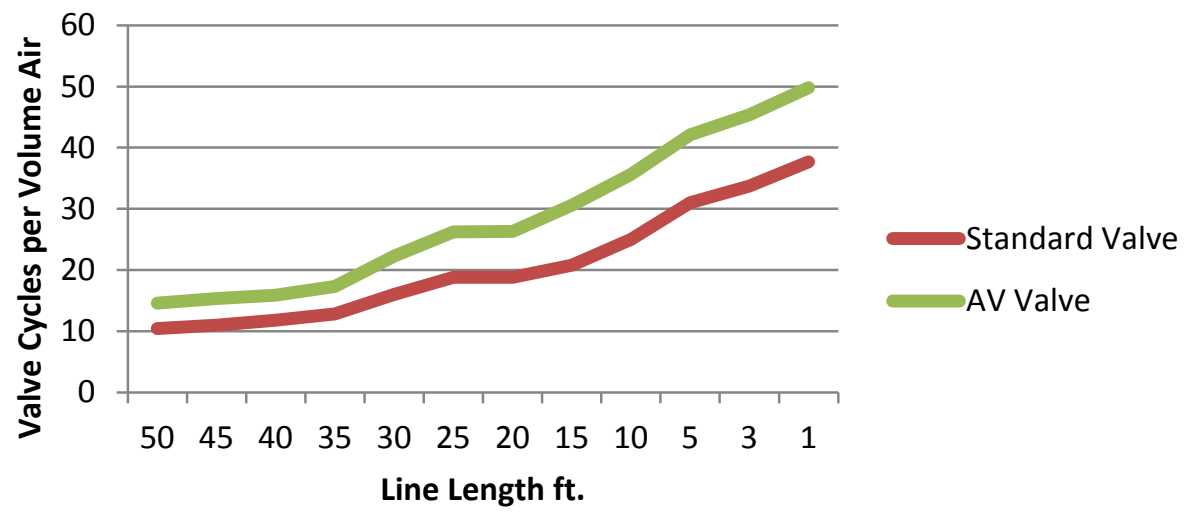

Fig. 5. Pressure Decay with $1.5 s \& 90 / 80$ psi vs. Tubing Length. 
Table 4. Pressure Decay with .75 s \& 80/70 psi vs. Tubing Length.

\begin{tabular}{|c|c|c|}
\hline $\begin{array}{c}\text { Line Length in ft. } \\
\text { Standard Commercial Valve } \\
\text { Averages (cycles) }\end{array}$ & $\begin{array}{c}\text { AV Valve } \\
\text { Averages (cycles) }\end{array}$ \\
\hline 50 & 20.2 & 36.4 \\
\hline 45 & 20 & 37.1 \\
\hline 40 & 20 & 37.7 \\
\hline 35 & 19.4 & 36.7 \\
\hline 30 & 19.6 & 36.3 \\
\hline 25 & 21 & 35.9 \\
\hline 20 & 21 & 36.2 \\
\hline 15 & 24.2 & 37 \\
\hline 10 & 29 & 40.9 \\
\hline 5 & 35 & 48.8 \\
\hline 3 & 37.7 & 51.8 \\
\hline 1 & 43.7 & 57.2 \\
\hline
\end{tabular}

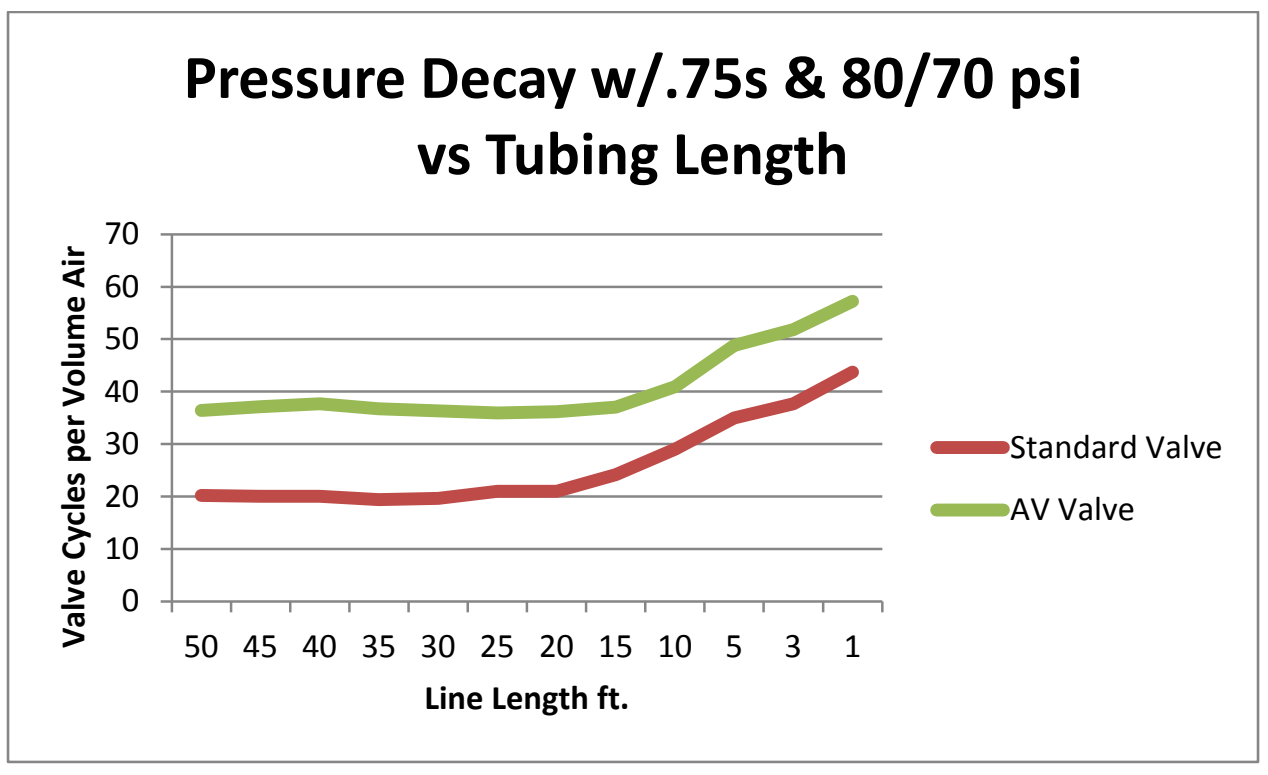

Fig. 6. Pressure Decay with $.75 \mathrm{~s} \& 80 / 70$ psi vs. Tubing Length. 
Table 5. Pressure Decay with $1.0 s \& 80 / 70$ psi vs. Tubing Length.

\begin{tabular}{|c|c|c|}
\hline $\begin{array}{c}\text { Line Length in ft. } \\
\text { Standard Commercial Valve } \\
\text { Averages (cycles) }\end{array}$ & $\begin{array}{c}\text { AV Valve } \\
\text { Averages (cycles) }\end{array}$ \\
\hline 50 & 16 & 25.3 \\
\hline 45 & 16 & 25.3 \\
\hline 40 & 15.8 & 25.2 \\
\hline 35 & 16 & 24.9 \\
\hline 30 & 18.6 & 27.4 \\
\hline 25 & 20.4 & 30.1 \\
\hline 20 & 20.4 & 30.4 \\
\hline 15 & 24.2 & 34.7 \\
\hline 10 & 28 & 40.3 \\
\hline 5 & 35 & 47.9 \\
\hline 3 & 38 & 51.8 \\
\hline 1 & 42.3 & 56.2 \\
\hline
\end{tabular}

\section{Pressure Decay w/1.0s \& 80/70 psi vs Tubing Length}

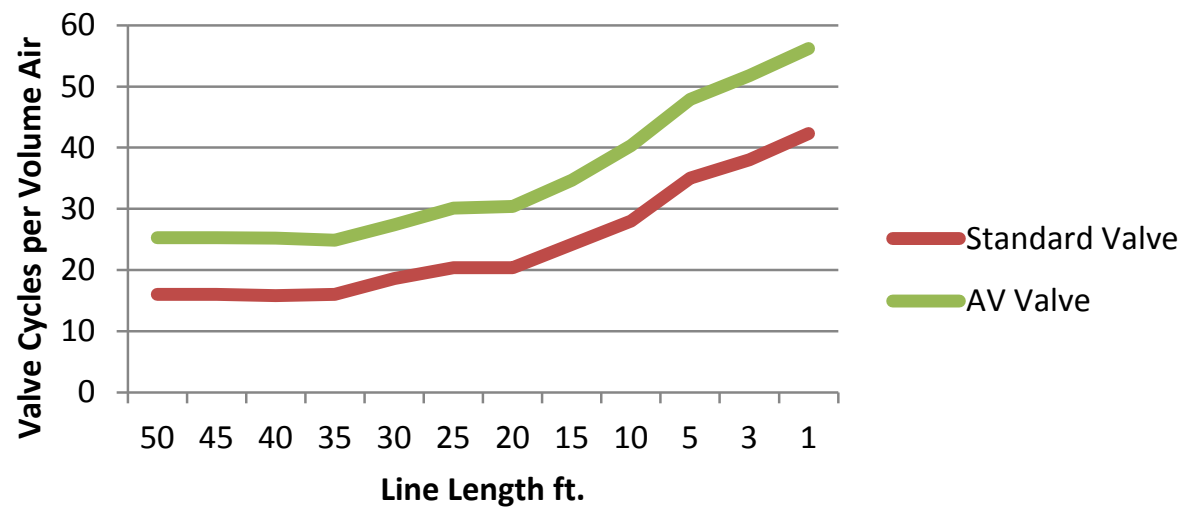

Fig. 7. Pressure Decay with $1.0 s \& 80 / 70$ psi vs. Tubing Length. 
Table 6. Pressure Decay with $1.5 s \& 80 / 70$ psi vs. Tubing Length.

\begin{tabular}{|c|c|c|}
\hline $\begin{array}{c}\text { Line Length in ft. } \\
\text { Standard Commercial Valve } \\
\text { Averages (cycles) }\end{array}$ & $\begin{array}{c}\text { AV Valve } \\
\text { Averages (cycles) }\end{array}$ \\
\hline 50 & 13 & 16.9 \\
\hline 45 & 13 & 17 \\
\hline 40 & 14 & 18.3 \\
\hline 35 & 14.8 & 19.9 \\
\hline 30 & 18.8 & 25.9 \\
\hline 25 & 21 & 30.1 \\
\hline 20 & 21.4 & 30.5 \\
\hline 15 & 24.4 & 35.2 \\
\hline 10 & 28.4 & 40.9 \\
\hline 5 & 35.7 & 48.7 \\
\hline 3 & 38.7 & 52.2 \\
\hline 1 & 43.3 & 57.2 \\
\hline
\end{tabular}

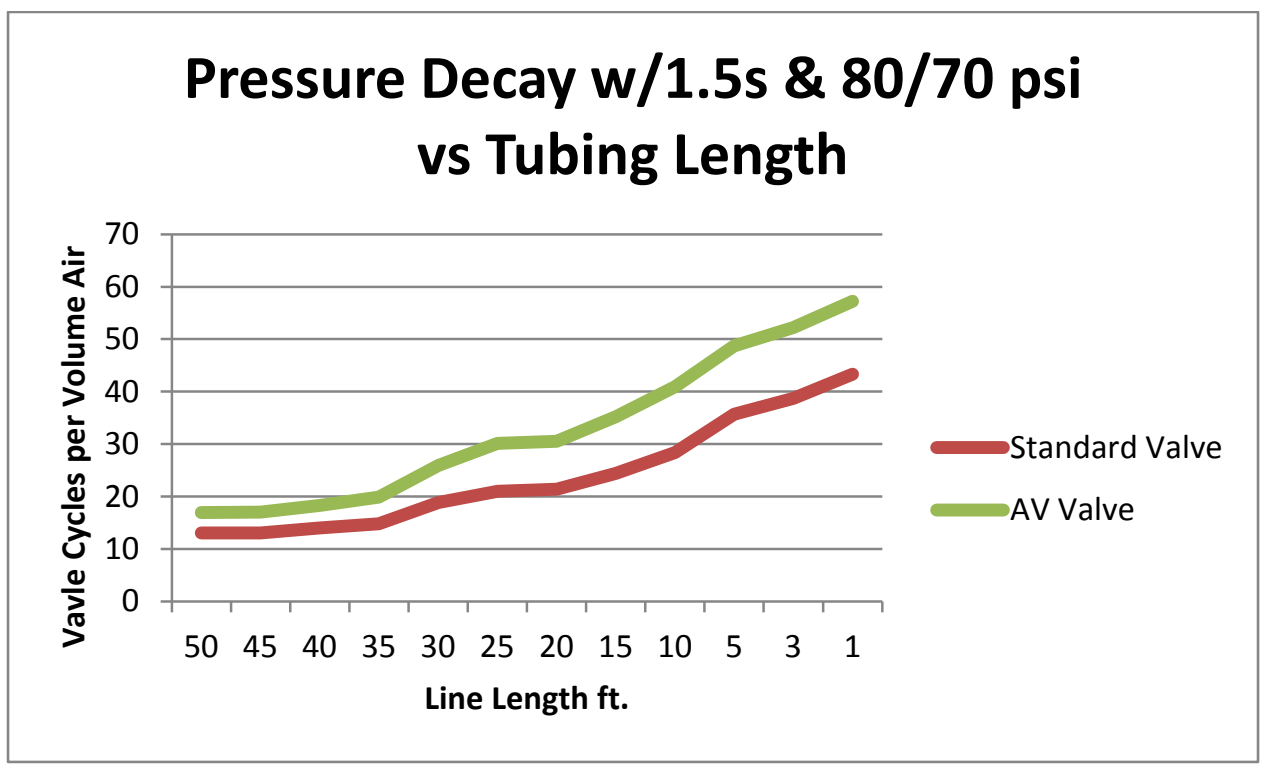

Fig. 8. Pressure Decay with $1.5 s \& 80 / 70$ psi vs. Tubing Length. 
Table 7. Pressure Decay with .75 s \& 60/50 psi vs. Tubing Length.

\begin{tabular}{|c|c|c|}
\hline $\begin{array}{c}\text { Line Length in ft. } \\
\text { Standard Commercial Valve } \\
\text { Averages (cycles) }\end{array}$ & $\begin{array}{c}\text { AV Valve } \\
\text { Averages (cycles) }\end{array}$ \\
\hline 50 & 27.5 & 51.5 \\
\hline 45 & 28.8 & 53 \\
\hline 40 & 28 & 53.4 \\
\hline 35 & 27.3 & 53.5 \\
\hline 30 & 27 & 52 \\
\hline 25 & 30 & 50.8 \\
\hline 20 & 30 & 51.7 \\
\hline 15 & 33.3 & 52 \\
\hline 10 & 39.3 & 55.6 \\
\hline 5 & 47.3 & 65.4 \\
\hline 3 & 51.7 & 69.4 \\
\hline 1 & 56.7 & 76.3 \\
\hline
\end{tabular}

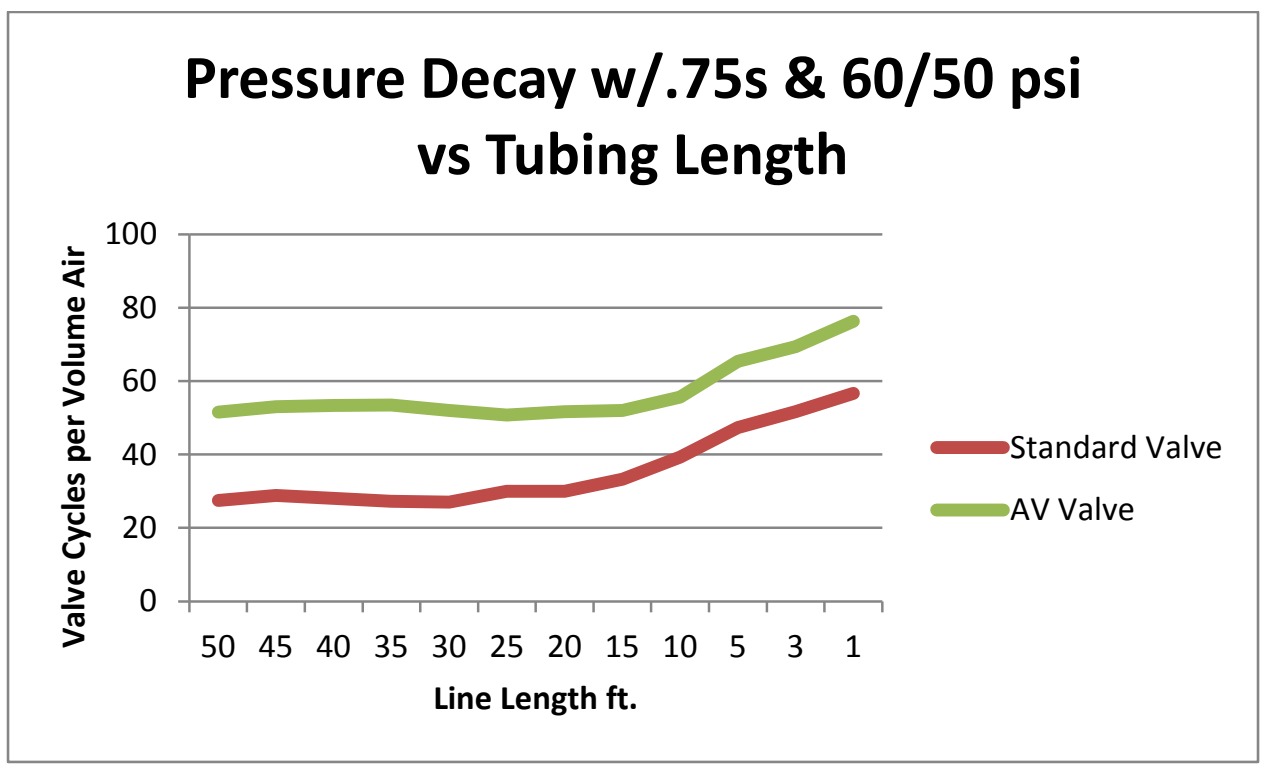

Fig. 9. Pressure Decay with $.75 \mathrm{~s} \& 60 / 50$ psi vs. Tubing Length. 
Table 8. Pressure Decay with $1.0 s \& 60 / 50$ psi vs. Tubing Length.

\begin{tabular}{|c|c|c|}
\hline $\begin{array}{c}\text { Line Length in ft. } \\
\text { Standard Commercial Valve } \\
\text { Averages (cycles) }\end{array}$ & $\begin{array}{c}\text { AV Valve } \\
\text { Averages (cycles) }\end{array}$ \\
\hline 50 & 22.4 & 36.7 \\
\hline 45 & 22 & 36.9 \\
\hline 40 & 22 & 36.6 \\
\hline 35 & 22 & 36.3 \\
\hline 30 & 26 & 38.2 \\
\hline 25 & 28.4 & 42.2 \\
\hline 20 & 28.8 & 42.5 \\
\hline 15 & 33 & 48.8 \\
\hline 10 & 39 & 55.9 \\
\hline 5 & 47.7 & 65.6 \\
\hline 3 & 52.3 & 69.7 \\
\hline 1 & 57.7 & 76.7 \\
\hline
\end{tabular}

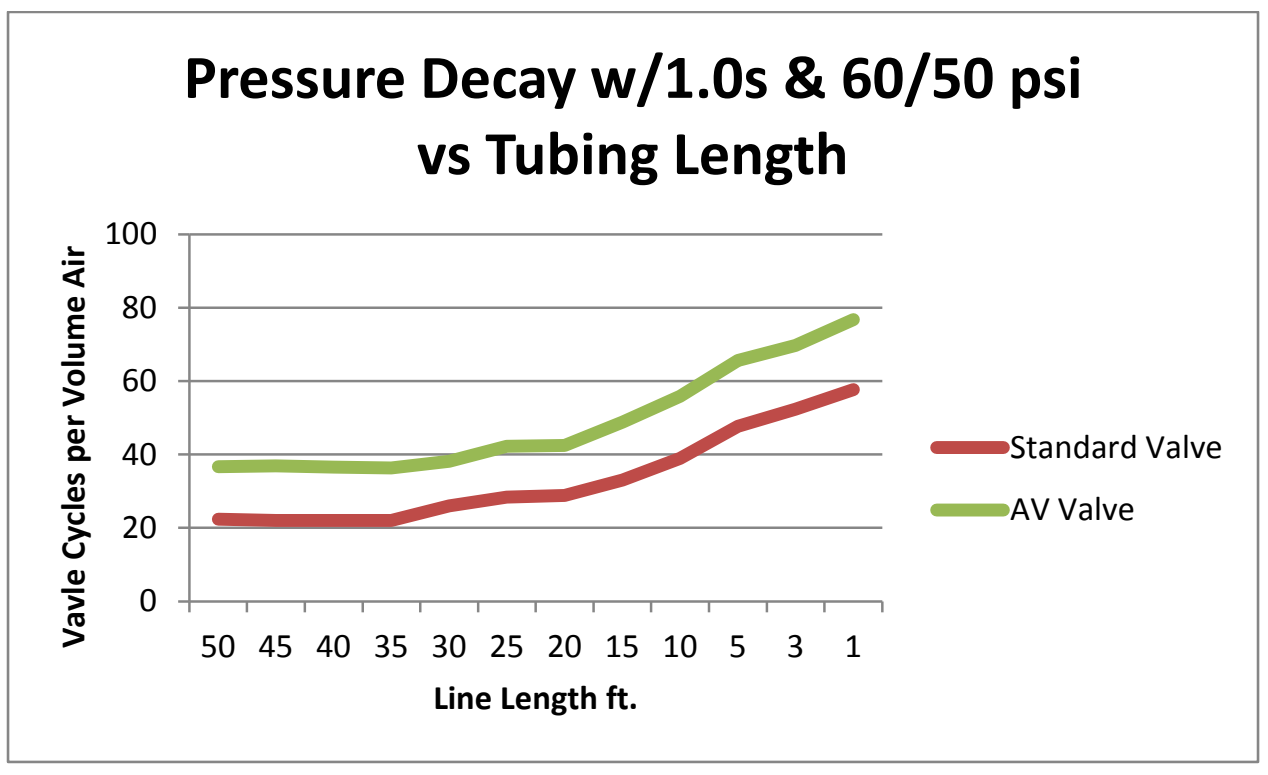

Fig. 10. Pressure Decay with $1.0 s \& 60 / 50$ psi vs. Tubing Length. 
Table 9. Pressure Decay with $1.5 s \& 60 / 50$ psi vs. Tubing Length.

\begin{tabular}{|c|c|c|}
\hline $\begin{array}{c}\text { Line Length in ft. } \\
\text { Standard Commercial Valve } \\
\text { Averages (cycles) }\end{array}$ & $\begin{array}{c}\text { AV Valve } \\
\text { Averages (cycles) }\end{array}$ \\
\hline 50 & 17.8 & 23.6 \\
\hline 45 & 18 & 24.6 \\
\hline 40 & 19.8 & 25.7 \\
\hline 35 & 20.2 & 28 \\
\hline 30 & 26 & 36.7 \\
\hline 25 & 29.4 & 42.3 \\
\hline 20 & 29.8 & 43.1 \\
\hline 15 & 33.8 & 49.3 \\
\hline 10 & 39.8 & 56.7 \\
\hline 5 & 48.7 & 66.6 \\
\hline 3 & 53.7 & 71.3 \\
\hline 1 & 58.7 & 77.9 \\
\hline
\end{tabular}

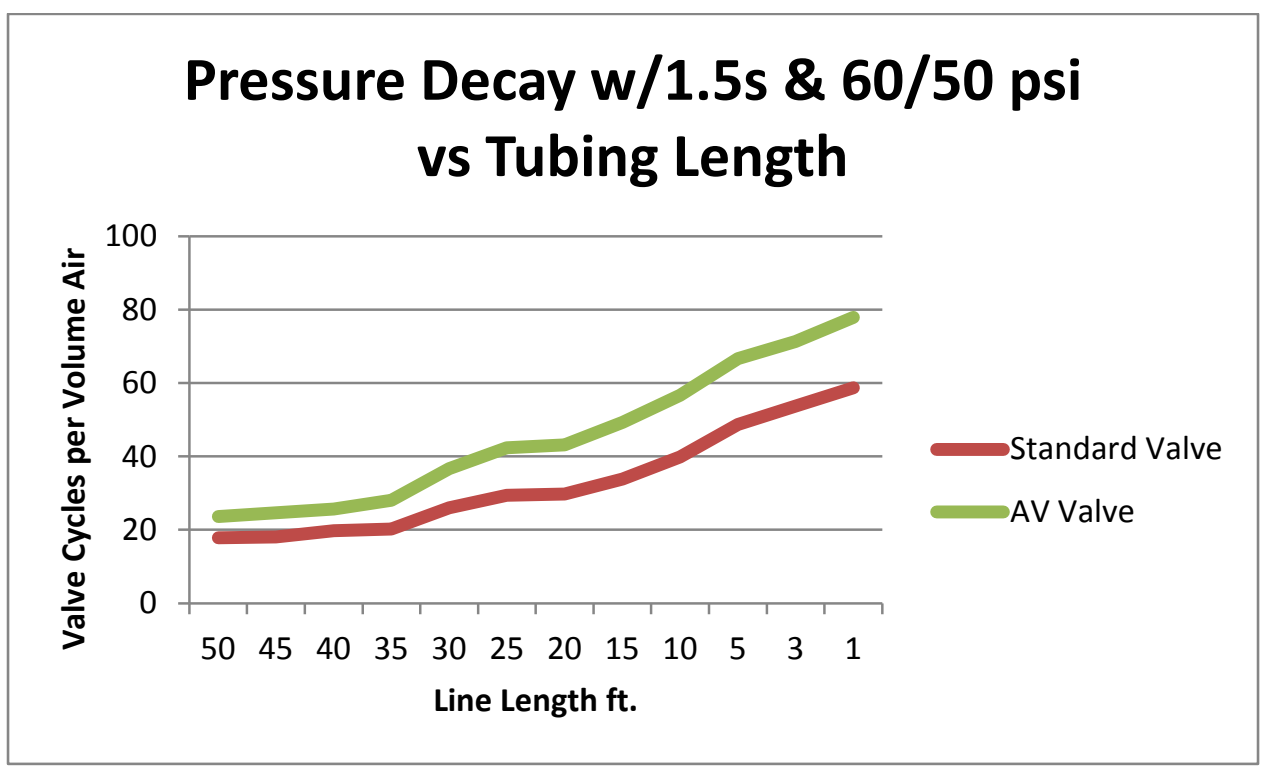

Fig. 11. Pressure Decay with $1.5 s$ \& 60/50 psi vs. Tubing Length. 
Table 10. Pressure Decay with .75s Mapped Against All Pressures and Line Lengths.

\begin{tabular}{|c|c|c|c|c|c|c|}
\hline $\begin{array}{c}\text { Line Length } \\
\mathrm{ft} .\end{array}$ & $\begin{array}{c}\text { Standard } \\
\text { Valve } \\
90 / 80 \mathrm{psi} \\
\text { cycles }\end{array}$ & $\begin{array}{c}\text { Standard } \\
\text { Valve } \\
80 / 70 \mathrm{psi} \\
\text { cycles }\end{array}$ & $\begin{array}{c}\text { Standard } \\
\text { Valve } \\
60 / 50 \mathrm{psi} \\
\text { cycles }\end{array}$ & $\begin{array}{c}\text { AV } \\
\text { Valve } \\
90 / 80 \mathrm{psi} \\
\text { cycles }\end{array}$ & $\begin{array}{c}\text { AV } \\
\text { Valve } \\
80 / 70 \mathrm{psi} \\
\text { cycles }\end{array}$ & $\begin{array}{c}\text { AV } \\
\text { Valve } \\
60 / 50 \mathrm{psi} \\
\text { cycles }\end{array}$ \\
\hline 50 & 17 & 20.2 & 27.5 & 30.9 & 36.4 & 51.5 \\
\hline 45 & 17 & 20 & 28.8 & 31.6 & 37.1 & 53 \\
\hline 40 & 17 & 20 & 28 & 31.6 & 37.7 & 53.4 \\
\hline 35 & 16.6 & 19.4 & 27.3 & 31.6 & 36.7 & 53.5 \\
\hline 30 & 16.8 & 19.6 & 27 & 30.8 & 36.3 & 52 \\
\hline 25 & 18 & 21 & 30 & 31 & 35.9 & 50.8 \\
\hline 20 & 18.2 & 21 & 30 & 31.1 & 36.2 & 51.7 \\
\hline 15 & 21 & 24.2 & 33.3 & 31.9 & 37 & 52 \\
\hline 10 & 24.4 & 29 & 39.3 & 35.2 & 40.9 & 55.6 \\
\hline 5 & 30 & 35 & 47.3 & 41.7 & 48.8 & 65.4 \\
\hline 3 & 32.7 & 37.7 & 51.7 & 45 & 51.8 & 69.4 \\
\hline 1 & 36.7 & 43.7 & 56.7 & 49.1 & 57.2 & 76.3 \\
\hline
\end{tabular}

\section{Pressure Decay .75s Mapped Against All Pressures and Line Lengths}

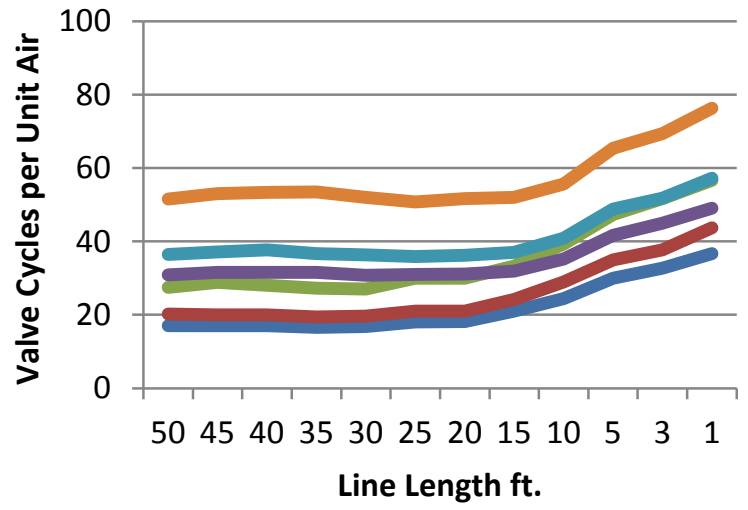

Standard Valve 90/80

$\longrightarrow$ Standard Valve 80/70

Standard Valve 60/50

$\longrightarrow$ AV Valve 90/80

AV Valve 80/70

AV Valve 60/50

Line Length $\mathrm{ft}$.

Fig. 12. Pressure Decay .75s Mapped Against All Pressures and Line Lengths. 
Table 11. Pressure Decay with 1.0s Mapped Against All Pressures and Line Lengths.

\begin{tabular}{|c|c|c|c|c|c|c|}
\hline $\begin{array}{c}\text { Line Length } \\
\mathrm{ft} .\end{array}$ & $\begin{array}{c}\text { Standard } \\
\text { Valve } \\
90 / 80 \mathrm{psi} \\
\text { cycles }\end{array}$ & $\begin{array}{c}\text { Standard } \\
\text { Valve } \\
80 / 70 \mathrm{psi} \\
\text { cycles }\end{array}$ & $\begin{array}{c}\text { Standard } \\
\text { Valve } \\
60 / 50 \mathrm{psi} \\
\text { cycles }\end{array}$ & $\begin{array}{c}\text { AV } \\
\text { Valve } \\
90 / 80 \mathrm{psi} \\
\text { cycles }\end{array}$ & $\begin{array}{c}\text { AV } \\
\text { Valve } \\
80 / 70 \mathrm{psi} \\
\text { cycles }\end{array}$ & $\begin{array}{c}\text { AV } \\
\text { Valve } \\
60 / 50 \mathrm{psi} \\
\text { cycles }\end{array}$ \\
\hline 50 & 14 & 16 & 22.4 & 22.1 & 25.3 & 36.7 \\
\hline 45 & 13.8 & 16 & 22 & 22.1 & 25.3 & 36.9 \\
\hline 40 & 13.8 & 15.8 & 22 & 21.7 & 25.2 & 36.6 \\
\hline 35 & 14 & 16 & 22 & 21.6 & 24.9 & 36.3 \\
\hline 30 & 16.8 & 18.6 & 26 & 23.5 & 27.4 & 38.2 \\
\hline 25 & 18 & 20.4 & 28.4 & 26.3 & 30.1 & 42.2 \\
\hline 20 & 18.8 & 20.4 & 28.8 & 26.5 & 30.4 & 42.5 \\
\hline 15 & 21 & 24.2 & 33 & 30.4 & 34.7 & 48.8 \\
\hline 10 & 24.6 & 28 & 39 & 35.4 & 40.3 & 55.9 \\
\hline 5 & 30.3 & 35 & 47.7 & 42 & 47.9 & 65.6 \\
\hline 3 & 33 & 38 & 52.3 & 45.3 & 51.8 & 69.7 \\
\hline 1 & 37 & 42.3 & 57.7 & 49.7 & 56.2 & 76.7 \\
\hline
\end{tabular}

\section{Pressure Decay 1.0s Mapped Against All Pressures and Line Lengths}

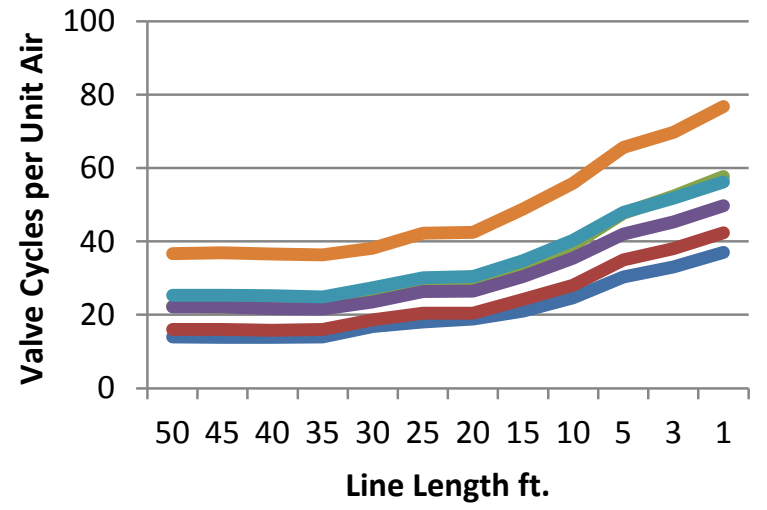

Standard Valve 90/80

Standard Valve 80/70

Standard Valve 60/50

$\longrightarrow$ AV Valve 90/80

AV Valve 80/70

AV Valve 60/50

Line Length $\mathrm{ft}$.

Fig. 13. Pressure Decay 1.0s Mapped Against All Pressures and Line Lengths. 
Table 12. Pressure Decay with 1.5s Mapped Against All Pressures and Line Lengths.

\begin{tabular}{|c|c|c|c|c|c|c|}
\hline $\begin{array}{c}\text { Line Length } \\
\mathrm{ft} .\end{array}$ & $\begin{array}{c}\text { Standard } \\
\text { Valve } \\
90 / 80 \mathrm{psi} \\
\text { cycles }\end{array}$ & $\begin{array}{c}\text { Standard } \\
\text { Valve } \\
80 / 70 \mathrm{psi} \\
\text { cycles }\end{array}$ & $\begin{array}{c}\text { Standard } \\
\text { Valve } \\
60 / 50 \mathrm{psi} \\
\text { cycles }\end{array}$ & $\begin{array}{c}\text { AV } \\
\text { Valve } \\
90 / 80 \mathrm{psi} \\
\text { cycles }\end{array}$ & $\begin{array}{c}\text { AV } \\
\text { Valve } \\
80 / 70 \mathrm{psi} \\
\text { cycles }\end{array}$ & $\begin{array}{c}\text { AV } \\
\text { Valve } \\
60 / 50 \mathrm{psi} \\
\text { cycles }\end{array}$ \\
\hline 50 & 10.4 & 13 & 17.8 & 14.6 & 16.9 & 23.6 \\
\hline 45 & 11 & 13 & 18 & 15.3 & 17 & 24.6 \\
\hline 40 & 11.8 & 14 & 19.8 & 15.9 & 18.3 & 25.7 \\
\hline 35 & 12.8 & 14.8 & 20.2 & 17.3 & 19.9 & 28 \\
\hline 30 & 16 & 18.8 & 26 & 22.3 & 25.9 & 36.7 \\
\hline 25 & 18.8 & 21 & 29.4 & 26.2 & 30.1 & 42.3 \\
\hline 20 & 18.8 & 21.4 & 29.8 & 26.3 & 30.5 & 43.1 \\
\hline 15 & 20.8 & 24.4 & 33.8 & 30.6 & 35.2 & 49.3 \\
\hline 10 & 25 & 28.4 & 39.8 & 35.6 & 40.9 & 56.7 \\
\hline 5 & 31 & 35.7 & 48.7 & 42.1 & 48.7 & 66.6 \\
\hline 3 & 33.7 & 38.7 & 53.7 & 45.4 & 52.2 & 71.3 \\
\hline 1 & 37.7 & 43.3 & 58.7 & 49.8 & 57.2 & 77.9 \\
\hline
\end{tabular}

\section{Pressure Decay 1.5s Mapped Against All Pressures and Line Lengths}

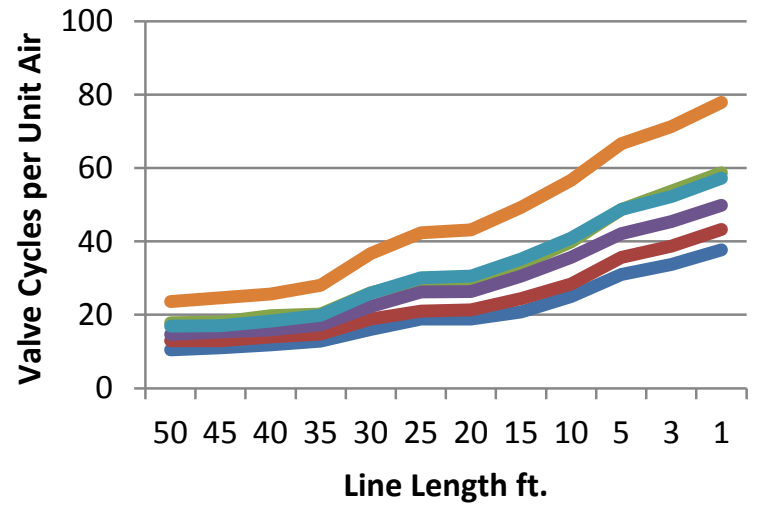

Standard Valve 90/80

Standard Valve 80/70

Standard Valve 60/50

$\longrightarrow$ AV Valve 90/80

AV Valve 80/70

AV Valve 60/50

Line Length $\mathrm{ft}$.

Fig. 14. Pressure Decay 1.5s Mapped Against All Pressures and Line Lengths. 
Table 13. Pressure Decay with $90 / 80$ psi vs. Time Constants and Line Length.

\begin{tabular}{|c|c|c|c|c|c|c|}
\hline $\begin{array}{c}\text { Line Length } \\
\text { ft. }\end{array}$ & $\begin{array}{c}\text { Standard } \\
\text { Valve } \\
.75 \mathrm{~s} \\
\text { cycles }\end{array}$ & $\begin{array}{c}\text { Standard } \\
\text { Valve } \\
1.0 \mathrm{~s} \\
\text { cycles }\end{array}$ & $\begin{array}{c}\text { Standard } \\
\text { Valve } \\
1.5 \mathrm{~s} \\
\text { cycles }\end{array}$ & $\begin{array}{c}\text { AV } \\
\text { Valve } \\
.75 \mathrm{~s} \\
\text { cycles }\end{array}$ & $\begin{array}{c}\text { AV } \\
\text { Valve } \\
1.0 \mathrm{~s} \\
\text { cycles }\end{array}$ & $\begin{array}{c}\text { AV } \\
\text { Valve } \\
1.5 \mathrm{~s} \\
\text { cycles }\end{array}$ \\
\hline 50 & 17 & 14 & 10.4 & 30.9 & 22.1 & 14.6 \\
\hline 45 & 17 & 13.8 & 11 & 31.6 & 22.1 & 15.3 \\
\hline 40 & 17 & 13.8 & 11.8 & 31.6 & 21.7 & 15.9 \\
\hline 35 & 16.6 & 14 & 12.8 & 31.6 & 21.6 & 17.3 \\
\hline 30 & 16.8 & 16.8 & 16 & 30.8 & 23.5 & 22.3 \\
\hline 25 & 18 & 18 & 18.8 & 31 & 26.3 & 26.2 \\
\hline 20 & 18.2 & 18.8 & 18.8 & 31.1 & 26.5 & 26.3 \\
\hline 15 & 21 & 21 & 20.8 & 31.9 & 30.4 & 30.6 \\
\hline 10 & 24.4 & 24.6 & 25 & 35.2 & 35.4 & 35.6 \\
\hline 5 & 30 & 30.3 & 31 & 41.7 & 42 & 42.1 \\
\hline 3 & 32.7 & 33 & 33.7 & 45 & 45.3 & 45.4 \\
\hline 1 & 36.7 & 37 & 37.7 & 49.1 & 49.7 & 49.8 \\
\hline
\end{tabular}

\section{Pressure Decay 90/80 psi vs Delay Time and Line Length}

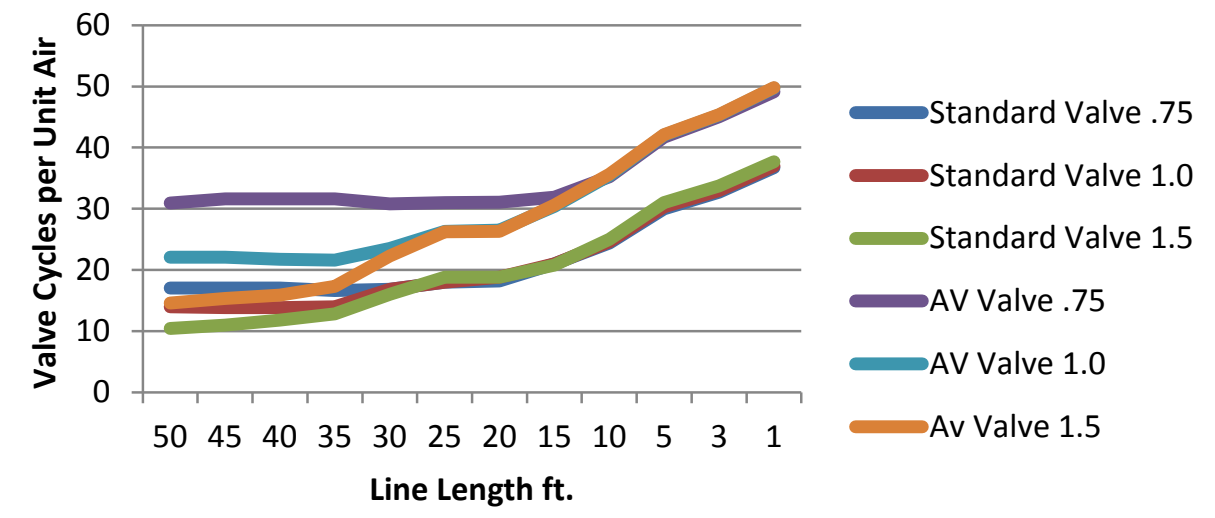

Fig. 15. Pressure Decay with $90 / 80$ psi vs. Time Constants and Line Length. 
Table 14. Pressure Decay with 80/70 psi vs. Time Constants and Line Length.

\begin{tabular}{|c|c|c|c|c|c|c|}
\hline $\begin{array}{c}\text { Line Length } \\
\text { ft. }\end{array}$ & $\begin{array}{c}\text { Standard } \\
\text { Valve } \\
.75 \mathrm{~s} \\
\text { cycles }\end{array}$ & $\begin{array}{c}\text { Standard } \\
\text { Valve } \\
1.0 \mathrm{~s} \\
\text { cycles }\end{array}$ & $\begin{array}{c}\text { Standard } \\
\text { Valve } \\
1.5 \mathrm{~s} \\
\text { cycles }\end{array}$ & $\begin{array}{c}\text { AV } \\
\text { Valve } \\
.75 \mathrm{~s} \\
\text { cycles }\end{array}$ & $\begin{array}{c}\text { AV } \\
\text { Valve } \\
1.0 \mathrm{~s} \\
\text { cycles }\end{array}$ & $\begin{array}{c}\text { AV } \\
\text { Valve } \\
1.5 \mathrm{~s} \\
\text { cycles }\end{array}$ \\
\hline 50 & 20.2 & 16 & 13 & 36.4 & 25.3 & 16.9 \\
\hline 45 & 20 & 16 & 13 & 37.1 & 25.3 & 17 \\
\hline 40 & 20 & 15.8 & 14 & 37.7 & 25.2 & 18.3 \\
\hline 35 & 19.4 & 16 & 14.8 & 36.7 & 24.9 & 19.9 \\
\hline 30 & 19.6 & 18.6 & 18.8 & 36.3 & 27.4 & 25.9 \\
\hline 25 & 21 & 20.4 & 21 & 35.9 & 30.1 & 30.1 \\
\hline 20 & 21 & 20.4 & 21.4 & 36.2 & 30.4 & 30.5 \\
\hline 15 & 24.2 & 24.2 & 24.4 & 37 & 34.7 & 35.2 \\
\hline 10 & 29 & 28 & 28.4 & 40.9 & 40.3 & 40.9 \\
\hline 5 & 35 & 35 & 35.7 & 48.8 & 47.9 & 48.7 \\
\hline 3 & 37.7 & 38 & 38.7 & 51.8 & 51.8 & 52.2 \\
\hline 1 & 43.7 & 42.3 & 43.3 & 57.2 & 56.2 & 57.2 \\
\hline
\end{tabular}

\section{Pressure Decay 80/70 psi vs Delay Time and Line Length}

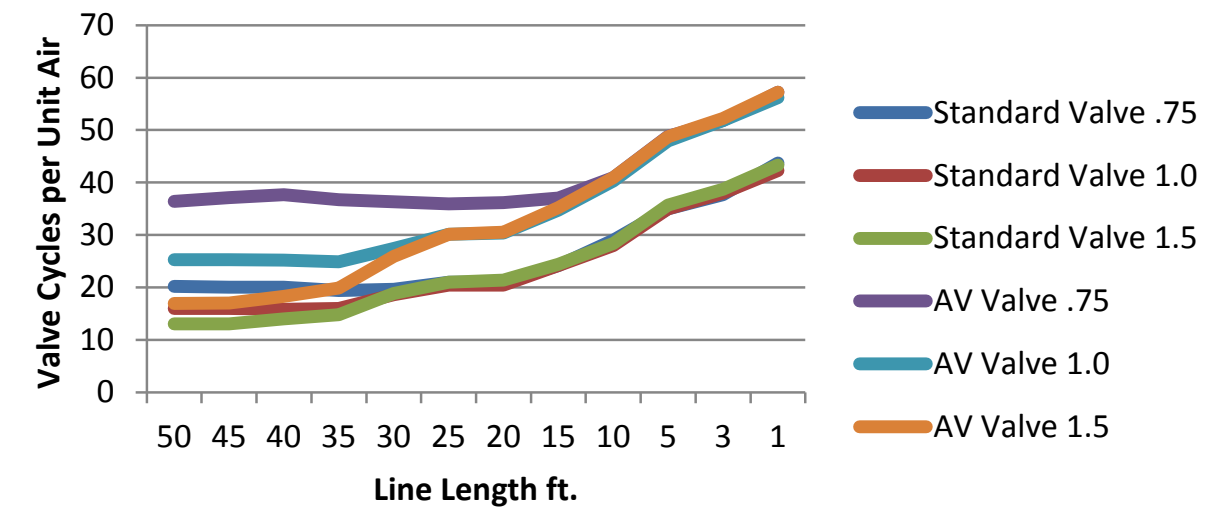

Fig. 16. Pressure Decay with $80 / 70$ psi vs. Time Constants and Line Length. 
Table 15. Pressure Decay with 60/50 psi vs. Time Constants and Line Length.

\begin{tabular}{|c|c|c|c|c|c|c|}
\hline $\begin{array}{c}\text { Line Length } \\
\text { ft. }\end{array}$ & $\begin{array}{c}\text { Standard } \\
\text { Valve } \\
.75 \mathrm{~s} \\
\text { cycles }\end{array}$ & $\begin{array}{c}\text { Standard } \\
\text { Valve } \\
1.0 \mathrm{~s} \\
\text { cycles }\end{array}$ & $\begin{array}{c}\text { Standard } \\
\text { Valve } \\
1.5 \mathrm{~s} \\
\text { cycles }\end{array}$ & $\begin{array}{c}\text { AV } \\
\text { Valve } \\
.75 \mathrm{~s} \\
\text { cycles }\end{array}$ & $\begin{array}{c}\text { AV } \\
\text { Valve } \\
1.0 \mathrm{~s} \\
\text { cycles }\end{array}$ & $\begin{array}{c}\text { AV } \\
\text { Valve } \\
1.5 \mathrm{~s} \\
\text { cycles }\end{array}$ \\
\hline 50 & 10.4 & 13 & 17.8 & 14.6 & 16.9 & 23.6 \\
\hline 45 & 11 & 13 & 18 & 15.3 & 17 & 24.6 \\
\hline 40 & 11.8 & 14 & 19.8 & 15.9 & 18.3 & 25.7 \\
\hline 35 & 12.8 & 14.8 & 20.2 & 17.3 & 19.9 & 28 \\
\hline 30 & 16 & 18.8 & 26 & 22.3 & 25.9 & 36.7 \\
\hline 25 & 18.8 & 21 & 29.4 & 26.2 & 30.1 & 42.3 \\
\hline 20 & 18.8 & 21.4 & 29.8 & 26.3 & 30.5 & 43.1 \\
\hline 15 & 20.8 & 24.4 & 33.8 & 30.6 & 35.2 & 49.3 \\
\hline 10 & 25 & 28.4 & 39.8 & 35.6 & 40.9 & 56.7 \\
\hline 5 & 31 & 35.7 & 48.7 & 42.1 & 48.7 & 66.6 \\
\hline 3 & 33.7 & 38.7 & 53.7 & 45.4 & 52.2 & 71.3 \\
\hline 1 & 37.7 & 43.3 & 58.7 & 49.8 & 57.2 & 77.9 \\
\hline
\end{tabular}

\section{Pressure Decay 60/50 psi vs Delay Time and Line Length}

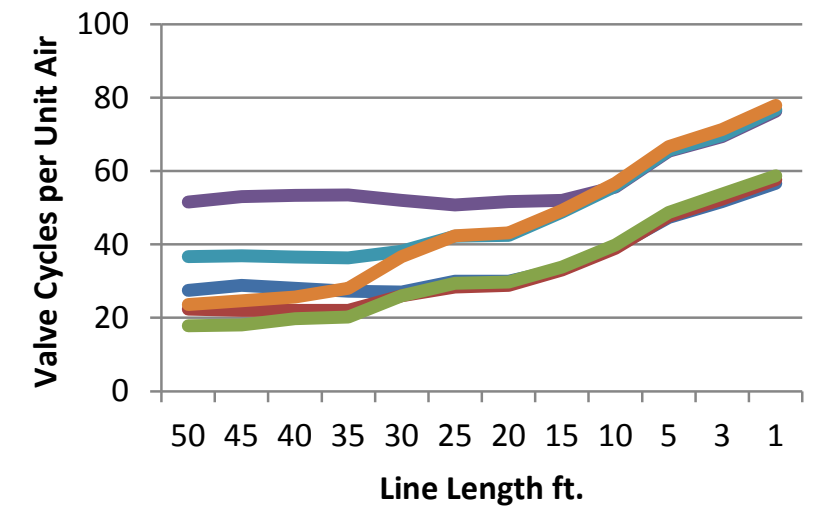

Standard Valve .75

$\Longrightarrow$ Standard Valve 1.0

Standard Valve 1.5

AV Valve .75

AV Valve 1.0

AV Valve 1.5

Fig. 17. Pressure Decay with 60/50 psi vs. Time Constants and Line Length. 
Table 16. Lickety Split Test at 80 psi vs. Line Length.

\begin{tabular}{|c|c|c|}
\hline $\begin{array}{c}\text { Line Length } \\
\mathrm{ft}\end{array}$ & $\begin{array}{c}\text { Standard Commercial Valve } \\
\text { Averages } \\
\text { Seconds per 30 Cycles }\end{array}$ & $\begin{array}{c}\text { AV Valve } \\
\text { Averages } \\
\text { Seconds per 30 Cycles }\end{array}$ \\
\hline 50 & 14.1 & 18.3 \\
\hline 45 & 12.9 & 17.1 \\
\hline 40 & 12.2 & 16.5 \\
\hline 35 & 11.2 & 15.4 \\
\hline 30 & 9 & 13.5 \\
\hline 25 & 8.1 & 12.4 \\
\hline 20 & 8.4 & 12.8 \\
\hline 15 & 7.5 & 12 \\
\hline 10 & 6.3 & 11.2 \\
\hline 5 & 5.5 & 10.2 \\
\hline 3 & 5.1 & 10.2 \\
\hline 1 & 4.8 & 10.2 \\
\hline
\end{tabular}

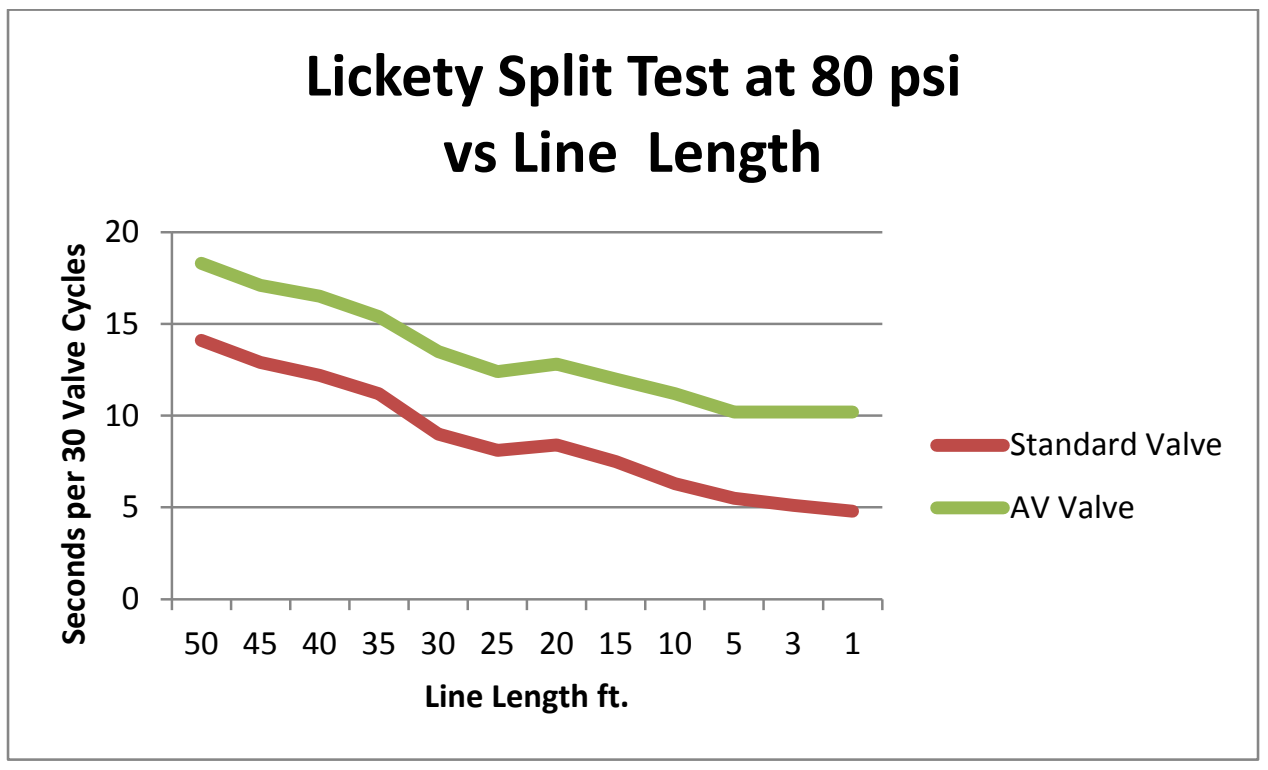

Fig. 18. Lickety Split Test at 80 psi vs. Line Length. 


\subsection{SOUND LEVEL COMPARISON}

A total of 12 tests were completed according to the experiment definition in section 2.3. Three test runs were completed for each of the four valves: standard commercial valve and AV valves E1, E2, and E3. The test run was the AeroValve Pressure Decay test with settings of max/min pressure of 90/80psi and a delay time of $1.00 \mathrm{~s}$.

Ambient sound levels in the room with no equipment running were measured at $40.5 \mathrm{~dB}$. The valve test sound levels measured in $\mathrm{dB}$ are presented in Table 17. The average of all standard commercial valve values was $92.1 \mathrm{~dB}$. The average of all tests for all three AV valves was $91.8 \mathrm{~dB}$. AV valve E1 was slightly louder than the standard commercial valve. AV valves E2 and E3 were slightly quieter than the standard commercial valve. In summary, there did not appear to be an appreciable statistical difference between the standard commercial valve and the AV valves in terms of sound level produced. However, further testing according to industry standards may reveal a slight difference between the two valve types.

Table 17. Sound Level Comparison Between Standard Commercial Valve and AV Valve.

\begin{tabular}{|c|c|c|c|c|}
\hline Valve & Test 1 & Test 2 & Test 3 & Average \\
\hline $\begin{array}{c}\text { Commercial } \\
\text { Valve }\end{array}$ & 92.3 & 92.3 & 91.8 & 92.1 \\
\hline AV E1 & 91.6 & 92.2 & 92.3 & 92.2 \\
\hline AV E2 & 91.7 & 91.7 & 91.5 & 91.6 \\
\hline AV E3 & 91.7 & 91.7 & 91.6 & 91.7 \\
\hline
\end{tabular}

\subsection{LOAD TEST COMPARISON}

The AV valves performed substantially better under load with respect to volume of air consumed per work completed efficiency than the standard commercial valve. It should also be noted that the AV valve improved performance as load increased for the forces tested. The data collected is shown in Table 18. Three instances of each test were run. Each table entry represents the average of the three data points for each set of test conditions. Fig. 19 provides a visual comparison of the two valve types.

For the particular line length tested, the average AeroValve advantage was $42 \%$ at zero force and $75 \%$ at $40.9 \mathrm{lbs}$. force. The standard commercial valve is flat (constant) across force applied by design. There was some variation between the three AV prototypes tested as shown in both the tabular and visual data; however the difference was not substantial, and the response profile was nearly identical. 
Table 18. Valve Load Comparison.

\begin{tabular}{|c|c|c|c|c|}
\hline Force in lbs & $\begin{array}{c}\text { Standard } \\
\text { Commercial Valve } \\
\text { cycles }\end{array}$ & $\begin{array}{c}\text { AV valve } \\
\text { E-1 } \\
\text { cycles }\end{array}$ & $\begin{array}{c}\text { AV valve } \\
\text { E-2 } \\
\text { cycles }\end{array}$ & $\begin{array}{c}\text { AV valve } \\
\text { E-3 } \\
\text { cycles }\end{array}$ \\
\hline 0 & 29.3 & 42.3 & 41 & 41.3 \\
\hline 24.8 & 29.3 & 50.7 & 49 & 46.7 \\
\hline 40.9 & 29.7 & 54 & 52 & 50.3 \\
\hline
\end{tabular}

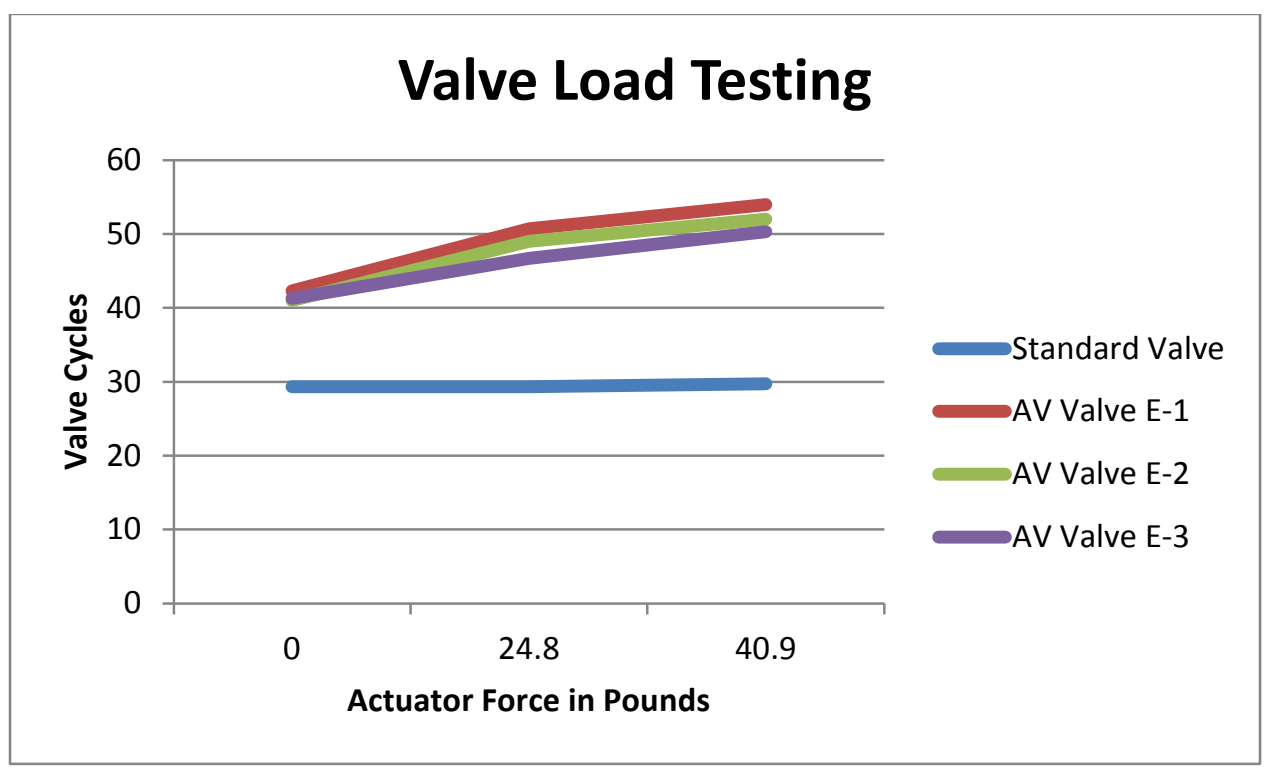

Fig. 19. Valve Load Comparison. 


\section{CONCLUSION}

This evaluation of the AV valves concludes that the valves performed as well as AeroValve stated, or better, in almost all cases analyzed where efficiency is concerned when efficiency is defined as volume of air consumed per unit of work done. Comparisons were made against a standard commercial valve with the same manifold mounting configuration and intended application range. Measuring air consumption per work completed, the AV valve was as much as $85 \%$ better than the standard commercial valve under some conditions, though absolute performance of both the standard commercial valve and the AV valve varied considerably with the chosen test parameters. However the AV valve was always more efficient than the standard commercial valve for air consumed per work completed for a given set of test conditions.

Besides performance validation, ORNL conducted the first AeroValve tests on the effects of line length on valve performance. It was thought that long pneumatic lines between the valve and actuator may store additional energy that could help valve performance. This effect was not seen, possibly due to the restriction posed by the small diameter supply tubing used in these applications. It appears that valve efficiency improves as line length decreases for both the standard commercial valve and the AV valves although the threshold where line length matters was different for each style of valve. Note that the data included in this testing include test data for line lengths from $50 \mathrm{ft}$. down to $1 \mathrm{ft}$. Total loop length is equal to twice the line length.

The AV style valve is slower than a standard commercial valve. Both valves improved (were quicker) as supply tubing length decreased; however the difference between the AV valve and the standard commercial valve also widened as supply line length decreased. For example the difference was only $30 \%$ at $50 \mathrm{ft}$. line length, but it was more than $100 \%$ at extremely short line lengths. Since AeroValve's intended target market is for applications where economy of operations is more important than speed of operation, this is not seen as an issue.

A limited test using a calibrated sound level meter was completed on sound level produced by the valves during actuation. In the limited test, there was no statistically observable difference in audible sound levels produced by either a standard commercial valve or AV valves. A more rigorous test to industry standards may provide more useful information; however subjectively, there did not seem to be any noticeable difference between the two valves when listening to them during the test. If there is a difference, it is not substantial.

A load test was also conducted using constant force springs of different spring constants. As load increased, the efficiency of the standard commercial valve was flat as expected; however the AV valve efficiency increased with load and was substantially more efficient than the standard commercial valve at all loads tested.

In summary, the experimental data collected support AeroValve's claim of greatly reduced air consumption while maintaining load carrying capacity. 


\section{LIST OF REFERENCES}

1. AeroValve web site, http://aerovalve.com/, August 31, 2014.

2. ANSI web store, http://webstore.ansi.org/RecordDetail.aspx?sku=ISO+3744\%3a2010, September 4, 2014. 